\title{
Phostensin Enables Lymphocyte Integrin Activation and Population of Peripheral Lymphoid Organs
}

Ho-Sup Lee ${ }^{1,2}$, Hao Sun ${ }^{1,2}$, Frédéric Lagarrigue ${ }^{1,3}$, Jay W. Fox , Nicholas E. Sherman ${ }^{4}$, Alexandre R. Gingras ${ }^{2}$, and Mark H. Ginsberg ${ }^{2,5}$

${ }^{2}$ University of California San Diego, Department of Medicine, La Jolla, CA

${ }^{3}$ Institut de Pharmacologie et Biologie Structurale, Université de Toulouse, Centre National de la Recherche Scientifique, Université Paul Sabatier, Toulouse, France

${ }^{4}$ University of Virginia, School of Medicine, Charlottesville, VA

${ }^{1}$ These authors contributed equally

${ }^{5}$ To whom correspondence should be addressed at:

15 Email: $\underline{\text { mhginsberg@ucsd.edu }}$

Phone: 1-858-822-6426

Address: 9500 Gilman Drive, MC 0726

La Jolla CA, 92093 


\section{SUMMARY}

Phostensin, a protein phosphatase 1 regulatory subunit, supports lymphocyte integrin-dependent functions by mediating dephosphorylation of Rap1 to stabilize the MIT complex thereby enabling the population of peripheral lymphoid organs 5 and T cell-mediated colitis. 


\section{ABSTRACT}

Rap1 GTPase drives assembly of the Mig-10/RIAM/lamellipodin-Integrin-Talin (MIT) complex that enables integrin-dependent lymphocyte functions. Here we

5 used tandem affinity tag-based proteomics to isolate and analyze the MIT complex and reveal that Phostensin (PTSN), a regulatory subunit of protein phosphatase 1, is a component of the complex. PTSN mediates de-phosphorylation of Rap1 thereby preserving the activity and membrane localization of Rap1 to stabilize the MIT complex. CRISPR/Cas9-induced deletion of PPP1R18, which encodes PTSN,

10 markedly suppresses integrin activation in Jurkat human T cells. We generated apparently healthy Ppp1r18 ${ }^{-}$mice that manifest lymphocytosis and reduced population of peripheral lymphoid tissues ascribable to defective activation of integrins $\alpha_{\llcorner} \beta_{2}$ and $\alpha_{4} \beta_{7}$. Ppp1r18\% $\mathrm{T}$ cells exhibit reduced capacity to induce colitis in a murine adoptive transfer model. Thus, PTSN enables lymphocyte integrin-

15 mediated functions by dephosphorylating Rap1 to stabilize the MIT complex. As a consequence, loss of PTSN ameliorates T cell-mediated colitis. 


\section{INTRODUCTION}

Integrin-mediated lymphocyte adhesion plays an essential role in lymphocyte development and their capacity to populate lymphoid organs and sites of

5 inflammation. Furthermore, by playing a critical accessory role in the formation of immunological synapses, integrins facilitate processes such as cytotoxic killing and antigen presentation. Integrins $\alpha_{\llcorner} \beta_{2}$ (LFA-1), $\alpha_{4} \beta_{1}$ (VLA-4) and $\alpha_{4} \beta_{7}$ (LPAM) are the lymphocyte integrins most commonly involved in these functions and each has served as a therapeutic target in autoimmune and inflammatory diseases(Hogg et

10 al., 2011; Ley et al., 2016). Lymphocyte integrins are constitutively in a low-affinity state until agonist stimulation induces high-affinity, a process operationally defined as "integrin activation"(Luo et al., 2007; Takagi et al., 2002; Xiong et al., 2001). Integrin activation is essential to their capacity to mediate the lymphocyte functions enumerated above(Hynes, 2002; Ley et al., 2007).

Stimulation via agonists such as chemokines or cytokines initiates a spectrum of intracellular signaling pathways to trigger integrin activation. These pathways ultimately converge upon the binding of talin1 to the integrin $\beta$ cytoplasmic tail(Kim et al., 2011; Lefort et al., 2012; Tadokoro et al., 2003; Ye et al., 2010), a final

20 common step in integrin activation. The small GTPase Rap1 is a dominant hub in the signaling pathways that control the talin-integrin-interaction(Bos, 2005). In conventional T cells, Rap1 utilizes RIAM as an effector for integrin activation, whereas in $\mathrm{CD}^{+} \mathrm{Foxp}^{+}$regulatory $\mathrm{T}$ cells, another $\mathrm{MRL}$ protein, Lamellipodin 
(LPD), makes a more important contribution(Sun et al., 2021). We previously showed that the MRL Protein-Integrin-Talin (MIT) complex forms the "sticky fingers" that drive cell protrusion and enable migratory pathfinding(Lagarrigue et al., 2015).

RIAM is abundant in hematopoietic cells. Unlike talin1 deletion, germline loss of RIAM in mice does not affect development, hemostasis, or platelet integrin function(Klapproth et al., 2015; Stritt et al., 2015; Su et al., 2015). However, RIAM plays an important role in the activation of $\beta_{2}$ and $\beta_{7}$ integrins in neutrophils,

10 macrophages and T cells(Boussiotis et al., 1997; Klapproth et al., 2015; MedranoFernandez et al., 2013; Su et al., 2015; Sun et al., 2021). $\beta_{1}$ and $\beta_{3}$ integrin functions are less affected by the absence of RIAM in these leukocytes(Klapproth et al., 2015; Su et al., 2015). RIAM-deficient mice exhibit significant leukocytosis associated with leukocyte adhesion deficiency and impaired leukocyte

15 extravasation. The apparently normal development and lack of bleeding in RIAM null mice, combined with their protection in models of autoimmune disease such as inflammatory bowel disease(Sun et al., 2021) or type I diabetes(Lagarrigue et al., 2017), suggests that targeting the regulation of the RIAM MIT complex could serve as a strategy to inhibit pathological inflammation or autoimmunity.

Here we analyzed the mechanisms that orchestrate the function of the MIT complex by using a tandem affinity purification tag to isolate the native complex and mass spectrometry to identify associated proteins. We focused our attention 
on Phostensin (PTSN), an actin-binding regulatory subunit of protein phosphatase 1 (PP1) encoded by the PPP1R18 gene(Kao et al., 2007) because PTSN is mainly expressed in leukocytes(Lin et al., 2011) and shares similar tissue distribution with RIAM. Here, we report that PTSN is physically associated with MIT complex and

5 that it stabilizes the complex by mediating the dephosphorylation of Rap1 thereby preserving Rap1 activity and enabling integrin activation. We generated viable and fertile $P p p 1 r 18^{-/-}$mice that exhibited impaired population of peripheral lymphoid tissues and defective activation of T cell integrins $\alpha_{\llcorner} \beta_{2}$ and $\alpha_{4} \beta_{7}$. Because Ppp1r18/- mice appear healthy yet have a defect in lymphocyte integrin function, we

10 suggest that PTSN may be a therapeutic target in autoimmune and inflammatory diseases. In support of this idea, Ppp1r18 ${ }^{-/-}$T cells manifested reduced capacity to induce colitis in an adoptive transfer model. In sum, we identify PTSN as a new regulator of lymphocyte integrin-mediated functions, show that it acts via stabilization of the RIAM MIT complex by dephosphorylating Rap1, and identify it

15 as a potential therapeutic target in T cell-mediated diseases. 


\section{METHODS}

\section{Cell lines and plasmids}

U2-OS, HEK293 and 293A cells were grown in DMEM supplemented with

$510 \%(v / v)$ FBS, non-essential amino acids, 1x Penicillin/Streptomycin, and 2mM Lglutamine at $37^{\circ} \mathrm{C}$ in a $5 \% \mathrm{CO}_{2}$ incubator. Jurkat T cells were from ATCC and cultured in RPMI supplemented with 10\%(v/v) FBS, non-essential amino acids, 1x Penicillin/Streptomycin, and 2 mM L-glutamine. U2-OS stable cell lines expressing $\alpha_{\| l b-S t r e p t a v i d i n}(\mathrm{SBP})-\beta_{3}$ or $\alpha_{\| l b}-\mathrm{SBP} \beta_{3}(\mathrm{D} 119 \mathrm{~A})$ were generated by lentiviral

10 infection of $\alpha_{\| l b-S B P}$ with $\beta_{3}$ or $\alpha_{\| b-S B P}$ with $\beta_{3}(D 119 A)$, respectively. Monoclonal cell populations were selected by flow cytometry.

Mammalian expression plasmids encoding full-length integrin $\alpha_{\| l b-S B P}$ and $\beta_{3}$ (WT, wild-type) or (D119A) were cloned into pcDNA3.1(-). Myc-, Myc-mCherry- or DsRed-tagged human $\beta$ - (aa 1-613) and $\alpha-P T S N ~(a a ~ 249-613)$ were cloned into

15 pcDNA3.1(-). Full-length RIAM cDNA was cloned into p3xFlag-CMV-7.1 (SigmaAldrich, St. Louis, MO). Constructs encoding EGFP-tagged full-length talin1 WT were previously described(Wegener et al., 2007). Coding sequences of $\beta$ - and $\alpha$ PTSN were cloned into pEGFP-C1 and p3xFlag-CMV-7.1 (Sigma-Aldrich). $\beta$ PTSN 4A mutation (residues K539, I540, S541 and F542 into four Ala) predicted

20 to block binding to protein phosphatase 1 (PP1)(Kao et al., 2007) was produced by site-directed mutagenesis. Bicistronic constructs expressing Flag-RIAM together with either Myc-His-Rap1a WT or S180A mutant were generated into pcDNA3.1(-). Plasmid encoding EGFP-tagged PP1 catalytic subunit $\mathrm{Y}$ was 
obtained from Addgene (Addgene plasmid \# 44225). Expression of PTSN was silenced in U2-OS and 293A cells by lentiviral transduction of a pLKO1 shRNA against both $\beta$ - and $\alpha$-PTSN (TRCN0000282572, Sigma-Aldrich). pLKO1 shRNA (SHC016V, Sigma-Aldrich) was used as a control.

\section{Antibodies and reagents}

Antibodies against talin (8d4, Sigma-Aldrich) and Flag (M2) were from SigmaAldrich. Antibody against DsRed (sc-33354) was from Santa Cruz Biotechnology (Dallas, TX). Anti-integrin $\alpha_{\mathrm{llb}}(\mathrm{PMI}-1)$, anti- $\beta_{3}(\mathrm{Rb8257}$ and Rb8053)(Frelinger et

10 al., 1990; Frelinger et al., 1988), activated anti- $\alpha_{\| b} \beta_{3}$ (Pac1)(Shattil et al., 1985) were described previously. Polyclonal anti-EGFP antibody was produced in rabbits immunized with recombinant EGFP. Anti-Flag M2 affinity gel was purchased from Sigma-Aldrich, and Pierce Streptavidin Plus UltraLink Resin and Pierce Monomeric Avidin Agarose were from Thermo Fisher Scientific (Rockford, IL).

15 3xFlag peptide (MDYKDHDGDYKDHDIDYKDDDDK) was synthesized by United BioSystems Inc (Hemdon, VA). Fluorophore-conjugated antibodies against CD3 (17A2, 2C11), B220 (RA3-6B2), CD49d (9F10), CD11a (M17/4), CD29 (HMß1-1), CD18 (M18/2) and $\beta_{7}$ (FIB 504) were purchased from BioLegend (San Diego, CA). Secondary AlexaFluor-labelled antibodies were from Jackson ImmunoResearch

20 (West Grove, PA). MojoSort mouse CD4 T cell isolation kit and SDF-1a were from BioLegend. Recombinant human VCAM-1-Fc, mouse ICAM-1-Fc and VCAM-1-Fc were from BioLegend. Recombinant mouse MAdCAM-1-Fc was from R\&D Systems (Minneapolis, MN). 
Antibody against $\beta$-PTSN was from Santa Cruz Biotechnology. To generate antibody against a-PTSN, mouse PTSN C-terminus (a.a. 429-594) was cloned into pETM-11 vector. His-PTSN fusion protein was solubilized from inclusion bodies with 6M urea and purified under denaturing conditions using His-Bind resin.

5 The protein was dialyzed against PBS multiple times and used to raise polyclonal rabbit antisera (Abgent, San Diego, CA).

\section{Purification of MIT complex by split-tandem affinity purification}

Sub-confluent U2-OS cells stably expressing integrin $\alpha_{l l b}-S B P$ and $\beta_{3}(D 119 A)$

10 were transfected with plasmids encoding Flag-RIAM or encoding the indicated Flag-tagged bait for 24-48 hrs. After washing with PBS, cells were harvested and lysates were prepared in lysis buffer (50 mM Tris- $\mathrm{HCl}(\mathrm{pH} 7.4), 100 \mathrm{mM} \mathrm{NaCl}, 0.5 \%$ NP-40, $0.5 \mathrm{mM} \mathrm{MgCl}_{2}, \quad 0.5 \mathrm{mM} \mathrm{CaCl}_{2}, 0.2 \mathrm{mM}$ GMP-PNP, $10 \mathrm{mM} \mathrm{N}-$ Ethylmaleimide, 1 MM Calpeptin, PhosStop and protease inhibitor cocktails). Cell

15 lysates were centrifuged at 22,000 $\mathrm{g}$ for $30 \mathrm{~min}$. The supernatant was collected and precleared with anti-mouse IgG coupled to agarose beads (Sigma-Aldrich) for $2 \mathrm{hrs}$ at $4^{\circ} \mathrm{C}$. Cell lysates were then loaded into anti-Flag affinity column and incubated for $4 \mathrm{hrs}$ at $4^{\circ} \mathrm{C}$. Bound proteins were eluted with $200 \mu \mathrm{g} / \mathrm{mL} 3 x$ Flag peptide after washing with lysis buffer. The eluate was subsequently loaded into

20 monomeric avidin agarose or streptavidin plus ultralink column (Thermo Fisher Scientific) and incubated for $2 \mathrm{hrs}$ at $4^{\circ} \mathrm{C}$. The associated proteins were washed and eluted by 5 mM D-biotin or boiled in Laemmli buffer for SDS-polyacrylamide gel electrophoresis (SDS-PAGE) and immunoblotting. 


\section{Identification of MIT-associated proteins}

The gel piece was transferred to a siliconized tube and washed and unstained in $200 \mu \mathrm{L} 50 \%$ methanol overnight. The gel pieces were dehydrated in acetonitrile,

5 rehydrated in $30 \mu \mathrm{L}$ of $10 \mathrm{mM}$ dithiothreitol in $0.1 \mathrm{M}$ ammonium bicarbonate and reduced at room temperature for $30 \mathrm{~min}$. The DTT solution was removed and the sample alkylated in $30 \mu \mathrm{L}$ of $50 \mathrm{mM}$ iodoacetamide in $0.1 \mathrm{M}$ ammonium bicarbonate at room temperature for $30 \mathrm{~min}$. The reagent was removed, and the gel pieces dehydrated in $100 \mu \mathrm{L}$ acetonitrile. The acetonitrile was removed, and

10 the gel pieces rehydrated in $100 \mu \mathrm{L}$ of $0.1 \mathrm{M}$ ammonium bicarbonateand the pieces completely dried by vacuum centrifugation. The gel pieces were rehydrated in 20 $\mathrm{ng} / \mu \mathrm{L}$ trypsin in $50 \mathrm{mM}$ ammonium bicarbonate and digested overnight at $37^{\circ} \mathrm{C}$ and the peptides formed extracted from the polyacrylamide in two $30 \mu \mathrm{L}$ aliquots of $50 \%$ acetonitrile/5\% formic acid. These extracts were combined and evaporated

15 to $15 \mu \mathrm{L}$ for MS analysis performed as previously described(Goldfinger et al., 2007).

\section{Immunoprecipitation}

Cells were harvested and lysed by NP-40 lysis buffer (50 mM Tris-HCl pH 7.4, 150

$20 \mathrm{mM} \mathrm{NaCl}, 0.5 \% \mathrm{NP}-40,0.5 \mathrm{mM} \mathrm{CaCl}_{2}, 0.5 \mathrm{mM} \mathrm{MgCl}, 1 \mu \mathrm{M}$ calpeptin, protease inhibitor cocktail) on ice for $15 \mathrm{~min}$. The lysate was centrifuged at $14,000 \mathrm{rpm}$ at $4^{\circ} \mathrm{C}$ for 15 min. Protein concentration of the lysate was determined by using a BCA assay (Thermo Fisher Scientific). The lysate was immunoprecipitated using 
designated primary antibodies with protein G resin (GenScript, Piscataway, NJ), or anti-Flag M2 affinity agarose gel at $4^{\circ} \mathrm{C}$. Then, immune complexes were washed for extended times with the lysis buffer and separated by SDS-PAGE gels. Proteins on the gel were transferred to nitrocellulose membrane and probed with indicated

5 primary and secondary antibodies.

\section{Flow cytometry}

Cells isolated from mouse tissues were washed and resuspended in PBS containing $0.1 \%$ BSA and stained with conjugated antibody for 30 min at $4{ }^{\circ} \mathrm{C}$.

10 Then cells were washed twice before flow cytometry analysis using an Accuri C6 Plus (BD Biosciences, Franklin Lakes, NJ). Data were analysed using FlowJo software (BD Biosciences).

\section{Integrin activation assay}

15 The activation state of $\alpha_{\| 1 b}(\mathrm{R} 995 \mathrm{~A}) \beta_{3}$ was assessed by measuring the binding of the ligand mimetic anti- $\alpha_{\| b} \beta_{3}$ monoclonal antibody PAC1 in two-color flow cytometric assays as described previously(O'Toole et al., 1994). PTSN expression in HEK293 stable cells expressing integrin $\alpha_{\| \prime b}(R 995 A) \beta_{3}$ was silenced by shRNA and the cells were transfected with shRNA-resistant EGFP-PTSN or EGFP vector

20 as a transfection marker. After 24 hrs, cells were suspended and stained with PAC1. Then, cells were washed and analyzed by flow cytometry. Background binding was measured in presence of the $\alpha_{\| \mathrm{lb}} \beta_{3}$ antagonist integrilin $(10 \mu \mathrm{M})$ whereas maximum binding was quantified upon addition of the anti-LIBS6 
monoclonal antibody(Frelinger et al., 1991) against $\alpha_{\Perp b} \beta_{3}(2 . \mu M)$. To measure the activation of $\alpha_{4} \beta_{1}$ (Rose et al., 2000), cells $\left(5 \times 10^{5}\right)$ were resuspended in HBSS buffer (Mediatech, Manassas, VA) containing $5 \mu \mathrm{g} / \mathrm{mL}$ human VCAM-1-Fc for 30 min at $37^{\circ} \mathrm{C}$. Afterward, cells were washed with $0.5 \mathrm{~mL}$ of HBSS buffer, then resuspended in the same buffer containing AlexaFluor647-conjugated anti-human antibody and incubated for 30 min on ice. Cells were washed twice prior to analysis by flow cytometry. Background binding was measured in presence of 5 mM EDTA whereas maximum binding was quantified upon addition of $1 \mathrm{mM} \mathrm{MnCl}_{2}$.

\section{Flow chamber assay}

A polystyrene Petri dish was coated with $10 \mu \mathrm{L}$ of MAdCAM-1/Fc, VCAM-1/Fc or ICAM-1/Fc alone or with SDF-1a $(2 \mu \mathrm{g} / \mathrm{ml})$ in coating buffer (PBS, $10 \mathrm{mM}$ $\mathrm{NaHCO} 3, \mathrm{pH} 9.0$ ) for $1 \mathrm{hr}$ at $37^{\circ} \mathrm{C}$ followed by blocking with $2 \% \mathrm{BSA}$ in coating buffer for $1 \mathrm{hr}$ at $37^{\circ} \mathrm{C}$. Cells were diluted $10^{6}$ cells $/ \mathrm{mL}$ in HBSS (10 mM HEPES, 1

$15 \mathrm{mM} \mathrm{Ca}^{2+} / \mathrm{Mg}^{2+}$ ) and immediately perfused through the flow chamber at a constant flow rate of $2 \mathrm{dyn} / \mathrm{cm}^{2}$. Adhesive interactions between the flowing cells and the coated substrates were assessed by manually tracking the motions of individual cells for $1 \mathrm{~min}$ as previously described(Sun et al., 2020; Sun et al., 2014). The motion of each adherent cell was monitored for $10 \mathrm{sec}$ following the initial adhesion

20 point, and two categories of cell adhesion were defined: rolling adhesion for cells with rolling motions for $>10 \mathrm{sec}$ with a velocity $>1 \mu \mathrm{m} / \mathrm{sec}$, whereas cells that remained adherent and stationary for $>10 \mathrm{sec}$ with a velocity $<1 \mu \mathrm{m} / \mathrm{sec}$ were 
defined as arrested adherent cells. The total adherent cell number includes both rolling adherent and firm adherent cells.

\section{Mice}

5 All animal experiments were approved by the Institutional Animal Care and Use Committee (IACUC) of the University of California, San Diego, and were conducted in accordance with federal regulations as well as institutional guidelines and regulations on animal studies. All mice were housed in specific pathogen-free conditions. C57BL/6J (CD45.1), C57BL/6J (CD45.2), and Rag1 ${ }^{-/}$mice were from

10 The Jackson Laboratory (Bar Harbor, ME). For experiments, 8-12-week-old mice were used. All injections of cells were performed during the light cycle. All experiments were performed by comparing mutant mice with littermate controls. Mononuclear cells were isolated from mesenteric lymph node (MLN), Peyer's patch (PP), peripheral lymph node (PLN), spleen (SP) and colonic lamina propria

15 as previously described. Ppp1r18 ${ }^{--}$mice were generated using a CRISPR/Cas9 approach at the University of California Irvine Transgenic Mouse Facility. The complex Cas9 mRNA/sgRNA/tracRNA $(3 \mu \mathrm{M})$ was injected into the pronuclei of C57BL/6N embryos. Surviving embryos were implanted into ICR pseudo-pregnant females and pregnancies went to full term. Tissue biopsies for genomic DNA were

20 taken from pups between 7-10 days. Mice were genotyped by PCR using forward primers 5'-ggacgacctgggacatagataca-3' and reverse primers 5'ttttcacacgccttcacaggta-3' followed by Sanger sequencing using forward primers 5'tccagacagcaggaagaggaag-3' and reverse primers 5'- tctacccagtcaggcatggt-3'. 
Founders were selected and backcrossed to the C57BL/6J strain ( $>5$ times) to establish the Ppp1r18 ${ }^{-/-}$strain. To generate the $P p p 1 r 18 \beta^{--}$mice, a similar CRISPR/Cas9 approach was used to inject a complexed Cas9 mRNA/sgRNA (3 $\mu \mathrm{M})$ into the pronuclei of C57BL/6NHsd embryos at the University of California San

5 Diego Transgenic Mouse Facility. One homozygous pup harbouring a 10 base pair deletion resulting in the appearance of a downstream premature stop codon was selected and backcrossed to the C57BL/6J strain (>5 times) to establish the Ppp1r18 $\beta^{---}$strain, which only lacks the $\beta$ form of PTSN. Mice were genotyped by PCR using forward primers 5'-ctgagcagagacccactgaaag-3' and reverse primers 5'-

10 ggatctggcttctgagtttgtgta-3' and amplicons were ran in 6\% TBE gels (Life Technologies, Carlsbad, CA).

\section{Mouse colitis models}

The adoptive T cell transfer model was described before(Sun et al., 2020). Briefly,

15 8-10-week-old mice were used. $5 \times 10^{5}$ CD4 ${ }^{+}$CD25-CD45RB ${ }^{\text {high }}$ conventional T cells from WT or Ppp1r18 ${ }^{-/-}$mice were injected intraperitoneally into Rag1/mice(Mombaerts et al., 1992). All comparisons were made between littermates. Mouse body weight was measured every day and values are shown as a percentage of the original weight. During the duration of the experiment, we

20 assessed the clinical progression of colitis by daily blinded scoring a disease activity index (DAI) by 2 independent investigators. The DAI is the combined score of body weight loss, stool consistency, and rectal bleeding and prolapse as follow:

1) Weight loss: 0 (no loss), 1 (1-5\%), 2 (5-10\%), 3 (10-20\%), 4 (>20\%); 2) Stool 
consistency: 0 (normal),1 (soft), 2 (very soft), 3 (diarrhea); 3) Rectal bleeding: 0 (none), 1 (red), 2 (dark red), 3 (gross bleeding); 4) Rectal prolapse: 0 (none), 1 (signs of prolapse), 2 (clear prolapse), 3 (extensive prolapse). Mice were sacrificed at week 15.

\section{Histology}

Formalin-fixed, paraffin-embedded Swiss-rolled colon sections of 4-mm thickness were mounted on glass slides and followed by hematoxylin and eosin staining or periodic acid-schiff staining. Images were acquired with a Nanozoomer Slide

10 Scanner (Hamamatsu, Hamamatsu City, Japan). Blinded histological scoring was performed by 2 investigators based on the method described previously(Erben et al., 2014) and total scoring range is 0-12.

\section{Blood counts}

15 Peripheral blood was collected from the retro-orbital plexus and transferred to tubes containing $\mathrm{K}+$.EDTA. Cell counts were performed using a Hemavet 950FS Hematology System programmed with mouse-specific settings (Drew Scientific. Miami Lakes, FL). All samples were tested in duplicate, and the mean for each animal was plotted.

\section{Real-time quantitative PCR analyses}

Total RNA was isolated from colon using tissue homogenizer (JXFSTPRP-24, ThunderSci, Shanghai, China) and TRIzol reagent according to the manufacturer's 
protocol (Thermo Fisher Scientific). For gene expression analysis, single-stranded cDNA was produced from $10 \mu \mathrm{g}$ total RNA of colon using SuperScript III FirstStrand synthesis and oligo-dT primers according to the manufacturer's protocol (Thermo Fisher Scientific). Kappa SybrFast qPCR kit (Kapa Biosystems,

5 Wilmington, MA) and thermal cycler (CFX96 Real-Time System; Bio-Rad, Hercules, CA) were used to determine the relative levels of the genes analysed (primer sequences are shown in Table 1) according to the manufacturer's protocol. The $2^{-\Delta \Delta C T}$ method was used for analysis, and data were normalized to GAPDH. Control values (Rag1 ${ }^{-/-}$mice injected with PBS) were set to 1 for comparisons.

\section{Statistics}

Statistical significance was assayed by a two-tailed $t$-test for single comparisons. ANOVA with a Tukey post hoc test was used to assay statistical significance for multiple comparisons. A p value $<0.05$ was considered significant.

15 Supplementary Material: Supplementary Table 1 contains the proteomic analysis of the purified MIT complex, Supplementary Figures 1-3. 


\section{RESULTS}

\section{PTSN is a component of the MIT complex}

To isolate an MIT complex, we devised a split tandem affinity purification method

5 that isolates the native complex formed prior to ligand engagement (Fig. 1A). We

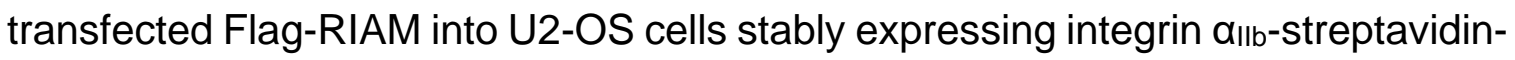
binding peptide (SBP) and $\beta_{3}(\mathrm{D} 119 \mathrm{~A})$ to form ligand binding-defective $\alpha_{\| b}(S B P) \beta_{3}(D 119 A)$. RIAM and associated proteins were isolated by anti-Flag affinity chromatography of cell lysates and the native proteins were eluted with 200

$10 \mu \mathrm{M}$ Flag peptide. The eluate was then passed through a streptavidin column to bind the $\alpha_{\| 1}(\mathrm{SBP})$ and the native MIT complex was eluted with $5 \mathrm{mM}$ biotin. In five experiments an average of $100 \mu \mathrm{g}$ of complex was isolated from $2 \times 10^{7}$ cells. The eluate of the streptavidin column was fractionated on SDS-PAGE and major protein components were visualized by immunoblotting with antibodies against

15 talin, integrin, or RIAM (right, Fig. 1B). In a proteomic analysis (Supplementary Table 1), we noted that PTSN was a prominent component of the isolated complex. PTSN, encoded by PPP1R18, is an actin binding regulatory subunit of protein phosphatase 1 (PP1). PTSN shares these biochemical functions with Phactr4, which modulates integrin signaling and cofilin activity to coordinate enteric neural

20 crest cell migration(Zhang et al., 2012). PTSN was also present in the LPD MIT complex (Fig. 1C). Importantly, PTSN was absent from the eluates of both Flag and streptavidin columns in the absence of Flag-RIAM (Fig. 1D). 


\section{Both isoforms of PTSN regulate integrin activation}

To examine the role of PTSN in integrin function, we used 293 cells constitutively expressing a recombinant talin-dependent(Tadokoro et al., 2003) activated integrin $\alpha_{\mathrm{Il}}(\mathrm{R} 995 \mathrm{~A}) \beta_{3}$. Silencing PTSN inhibited activation and co-expressing shRNA-

5 resistant PTSN rescued activation of this integrin (Fig. 2A,B). PTSN has a short and long isoform, termed $\alpha$ and $\beta$ respectively(Lin et al., 2014), and both contain actin and PP1 binding domains (Fig. 2C). Either isoform associated with RIAM (Fig. 2D) and could rescue integrin activation (Fig.2E).

Analysis using the human proteome map

10 (http://www.humanproteomemap.org/batch.php) confirmed that both RIAM and PTSN are particularly well expressed in lymphoid cells (Fig. 3A). We therefore used CRISPR/Cas9 mutagenesis to inactivate PPP1R18 in the Jurkat T cell line and observed a marked reduction in basal and phorbol myristate acetate (PMA)stimulated activation of an endogenous integrin (Fig. 3B,C). In both cases

15 activation was rescued by re-expressing either $\alpha$ - or $\beta$-PTSN. Thus, both isoforms of PTSN regulate integrin activation in a model system and a human $\mathrm{T}$ cell line.

\section{PTSN regulates the assembly of the MIT complex}

To investigate how PTSN regulates integrin activation, we tested the role of PTSN

20 in the assembly of the RIAM MIT complex. We silenced PTSN expression in cells expressing recombinant Flag-RIAM and integrin $\alpha_{\mathrm{Ilb}} \beta_{3}$ and purified Flag-RIAM by immuno-affinity chromatography (Fig. 4A). Silencing PTSN dramatically reduced the association of both integrin $\beta_{3}$ and talin with RIAM, indicating disassembly of 
the MIT complex. The complex was assembled when shRNA-resistant $\beta$-PTSN was co-expressed with the PTSN shRNA (Fig. 4 B-E). Thus, PTSN regulates the assembly of the MIT complex.

Activated Rap1 drives the formation of the MIT complex and results integrin

5 activation, leading us to examine the potential role of PTSN in regulating Rap1. Protein kinase A (PKA) phosphorylation of Rap1 inhibits Rap1 activity by decreasing GTP loading and disrupting membrane localization(Takahashi et al., 2013). To assess whether silencing PTSN could affect Rap1 phosphorylation, Rap1 was immunoprecipitated from cells in which endogenous PTSN expression

10 was silenced by PTSN-specific shRNA. Rap1 phosphorylation was assessed by an antibody specific for phosphorylated PKA substrates. Silencing endogenous PTSN led to increased Rap1 phosphorylation and overexpression of shRNA resistant PTSN abolished Rap1 phosphorylation (Fig. 5A). To examine the specificity of increased phosphorylation by PTSN silencing, we examined cAMP

15 Response Element-Binding Protein (CREB), an abundant PKA substrate. Silencing PTSN expression had no effect on Forskolin-induced CREB phosphorylation (Fig. 5B). Rap1a is phosphorylated at $\mathrm{COOH}$-terminal Serine residue 180 by PKA both in vivo and in vitro(Takahashi et al., 2013). To directly address if Rap1 de-phosphorylation is important for RIAM MIT complex assembly,

20 we asked if phosphorylation resistant Rap1a mutant (S180A) could support RIAM MIT assembly when PTSN was silenced. We generated IRES (internal ribosome entry site)-based bicistronic construct (Fig. 5C) expressing both Flag-RIAM and Myc-Rap1a(S180A) and transfected it into the cells expressing integrin $\alpha_{\| \mathrm{lb}} \beta_{3}$ and 
Flag-RIAM. Expression of Rap1a(S180A) but not wild type Rap1a restored the association of integrin $\beta_{3}$ with RIAM, indicative of the intact RIAM MIT complex, in PTSN silenced cells (Fig. 5C). Importantly, silencing PTSN did not affect the similar expression levels of Rap1a(S180A) or of Rap1a, nor did it affect expression of

5 Flag-RIAM or a-tubulin (Fig. 5C). Together, these data show that PTSN stabilizes the MIT complex and thus, integrin activation by antagonizing the phosphorylation of Rap1.

PTSN is a PP1 regulatory subunit and we confirmed that mutation of the PP1 catalytic subunit (PP1C) binding site disrupted its association with PTSN (Fig. 5E).

10 This PP1C binding-defective mutant PTSN was unable to support integrin activation (Fig. 5F,G). PTSN is an actin associated protein(Lai et al., 2009; Wang et al., 2012), therefore we tested if silencing PTSN expression could affect the phosphorylation of regulators of actin dynamics whose activities are controlled by phosphorylation. Silencing of PTSN increased the phosphorylation of Cofilin

15 (Supplementary Fig. 1A) and VASP (Supplementary Fig. 1B). Overexpression of shRNA resistant PTSN, either $\alpha$ or $\beta$ isoforms, abolished the increased phosphorylation of cofilin (Supplementary Fig. 1C). Thus, in addition to preserving the activity of Rap1 and thus integrins, PTSN can induce de-phosphorylation of regulators of actin dynamics.

\section{Ppp1r18 $^{-/-}$mice are viable, fertile, and manifest reduced integrin activation}

The foregoing data show that PTSN, a component of the MIT complex, stabilizes the assembly of that complex and resulting integrin activation by regulating the 
phosphorylation of Rap1. We therefore created Ppp1r18 ${ }^{-/}$mice to assess a potential role for PTSN in vivo. We devised three different CRISPR/Cas9 strategies to inactivate Ppp1r18. We first used a combination of two different gRNAs to introduce 10 stop codons downstream of the codon for the initiator Methionine

5 residue 428 of the $\alpha$ form of PTSN (Fig. 6A). To eliminate possible off target effects, we used different guide RNAs to delete the whole coding sequence of Exon 1 that contains initiator Methionine of both $\alpha$ and $\beta$ forms of PTSN (Supplementary Fig. 2A). In both cases, homozygous Ppp1r18 ${ }^{-/-}$offspring mice were viable and fertile and their splenocytes lacked both PTSN $\alpha$ and $\beta$ isoforms (Fig. 6B, Supplementary

10 Fig. 2B), and exhibited no change in expression of integrins $\alpha_{L}, \alpha_{4}, \beta_{2}$, $\beta_{1}$, or $\beta_{7}$ (Fig. 6C) or of RIAM (Fig. 6D) in comparison with wild type littermates. To specifically inactivate the $\beta$ form of PTSN, we used a gRNA upstream of the alternative translation start site at Methionine residue 428 resulting in a 10-base pair deletion which provokes a premature stop codon (Supplementary Fig. 3A) and

15 absence of the $\beta$-PTSN form, but intact expression of the $\alpha$ form, in splenocytes (Supplementary Fig. 3B). Homozygotes of $P p p 1 r 18 \beta^{--}$mice, lacking only the $\beta$ form of PTSN, were viable and fertile and their splenocytes expressed a normal complement of integrins $\alpha_{L}, \alpha_{4}, \beta_{2}, \beta_{1}$, or $\beta_{7}$ (Supplementary Fig. $3 C$ ) or of RIAM (Supplementary Fig. 3D).

Ppp 1 r18 ${ }^{-/}$mice of both genotypes lacking both forms of PTSN, exhibited a $\sim$ twofold increase in blood leukocytes that affected both lymphocytes and neutrophils (Fig. 6E) and an accompanying decrease in $\mathrm{T}$ and $\mathrm{B}$ cells in peripheral lymphatic 
organs (Fig. 6F). The leukocytosis in these mice combined with a reduction in lymphocytes in peripheral lymphatic organs is similar to that observed in RIAM deficient Apbb1ip/-- mice(Klapproth et al., 2015) (Su et al., 2015) and is explained by the reduction in $\mathrm{T}$ cell (Fig. 6G-I) and B cell (Fig. 6J) integrin activation.

5 Furthermore, Ppp1r18 ${ }^{-/-}$splenocytes exhibited increased phosphorylation of cofilin (Supplementary Fig. 1D) and VASP (Supplementary Fig. 1E) similar to that observed in U2-OS cells (Supplementary Fig. 1A,B). We were unable to immunoprecipitate sufficient Rap1 from splenocytes to analyze its phosphorylation. Thus, PTSN enables activation of lymphocyte integrins and

10 population of peripheral lymphoid organs.

In sharp contrast to Ppp1r18 ${ }^{-/}$mice, $P p p 1 r 18 \beta^{-/-}$mice exhibited blood counts indistinguishable from those of wild type littermates (Supplementary Fig. 3E). Consistent with the absence of leukocytosis, $P p p 1 r 18 \beta^{-/-} \mathrm{T}$ cells exhibited similar

15 activation of $T$ cell $\alpha_{\llcorner} \beta_{2}$ and $\alpha_{4} \beta_{1}$ integrins as judged by adhesion on ICAM-1, or VCAM-1 respectively (Supplementary Fig. 3G,H). The preservation of lymphocyte integrin function was manifested phenotypically by the normal population of peripheral lymphatic tissues by B cells and $\mathrm{T}$ cells (Supplementary Fig. 3F). Because Ppp1r18 $\beta^{-/-}$mice exhibited no obvious phenotype, $\alpha-P T S N$ is sufficient 20 for these lymphocyte functions.

\section{Ppp1r18 $^{-/-}$T cells exhibit reduced capacity to induce colitis}


Because PTSN null mice were apparently healthy, yet exhibited defects in T cell integrin activation, we hypothesized that their $\mathrm{T}$ cells might lack the capacity to provoke auto-immune inflammation. We induced experimental autoimmune colitis(Sun et al., 2020) by infusing $\mathrm{CD}^{+}{ }^{+} \mathrm{CD} 25^{-} \mathrm{CD} 45 \mathrm{RB}^{\text {high }} \mathrm{T}$ cells (Tconv) from

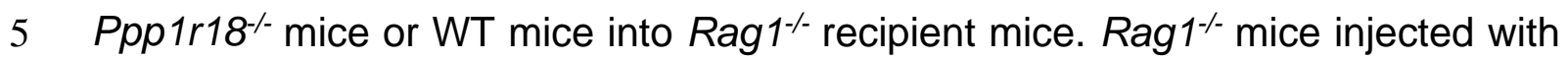
WT Tconv manifested a progressive loss in bodyweight 20-30 days after the infusion (Fig. 7A). Half of these mice died by 100 days (Fig. 7B). In contrast, Rag1/- mice injected with Ppp1r18 ${ }^{-/-}$Tconv exhibited a little loss of bodyweight and only $10 \%$ of these mice died by 100 days (Fig. 7A,B).

10 Histologically, wild-type Tconv infusion led to a severe colitis in Rag1/- mice, with almost complete loss of crypts, dense infiltrates of leukocytes in both mucosa and submucosa, and thickening of the bowel wall (Fig. 7C). By contrast, the inflammatory infiltrates in the Rag1/- mice infused with Ppp1r18 ${ }^{-/-}$Tconv were much reduced and less tissue damage was observed (Fig. 7C). Blinded histological

15 scoring for inflammatory cell infiltrates and epithelial damage confirmed a reduction

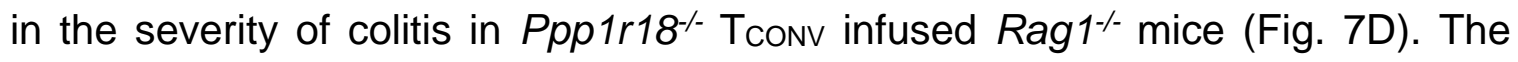
difference in inflammatory cell infiltration between Ppp1r18 ${ }^{--}$and wild-type Tconv infused $\mathrm{Rag1}^{-/-}$mice was confirmed by the reduction in colonic expression of pro-

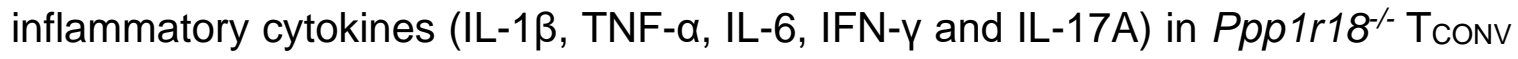

20 recipients (Fig. 7E). Thus, the defect in integrin activation in PTSN null $\mathrm{CD}^{+} \mathrm{T}^{-}$ cells is associated with impaired capacity to induce intestinal inflammation. 


\section{DISCUSSION}

The MIT complex plays an essential role in leukocyte integrin activation and thus in the trafficking and functions of lymphocytes in immunity and

5 immunopathology(Su et al., 2015). Here we report that an actin binding regulatory subunit of PP1, PTSN, encoded by the Ppp1r18 gene(Kao et al., 2007), stabilizes the MIT complex by mediating the dephosphorylation of Rap1 thereby preserving Rap1 activity. The stabilization of the MIT complex enables lymphocyte integrin activation and cell adhesion. Ppp1r18 ${ }^{-/}$mice are viable, fertile, and apparently

10 healthy. These mice exhibit reduced lymphocyte population of peripheral lymphoid tissues associated with lymphocytosis in peripheral blood, findings ascribable to defective activation of lymphocyte integrins $\alpha_{\llcorner} \beta_{2}$ and $\alpha_{4} \beta_{7}$. Furthermore, Ppp1r181- T cells manifested reduced capacity to induce colitis in an adoptive transfer model. Thus, PTSN is a regulator of $\mathrm{T}$ cell integrin-mediated functions that

15 stabilizes the RIAM MIT complex by dephosphorylating Rap1. In spite of this defect in T cell integrin function Ppp1r18 $8^{-/}$mice appear healthy suggesting that PTSN may be a therapeutic target in T cell mediated autoimmune diseases.

PTSN is physically associated with MIT complex and enables integrin activation

20 by mediating de-phosphorylation of Rap1, thereby stabilizing the complex. PTSN was associated with the MIT complex formed by a ligand binding-defective integrin(Loftus et al., 1990) explaining why this association can form in nonadherent lymphocytes. Activation of integrins in lymphocytes requires Rap1(Su et 
al., 2015) and we find that PTSN helps maintain Rap1 in a functional nonphosphorylated state. In particular, we find that silencing of phostensin destabilizes the MIT complex and this destabilization can be prevented by a nonphosporylatable mutant of Rap1a. In addition to blocking membrane association of

5 Rap1, Rap1 phosphorylation results in prolonged activation of ERK 1/2(Takahashi et al., 2017), an event that can also suppress integrin activation(Hughes et al., 1997) and assembly of the MIT complex(Lagarrigue et al., 2015). Thus, PTSN joins Phactr4(Zhang et al., 2012) as actin-associated protein phosphatase 1 regulators that modulate integrin functions.

Ppp1r18 ${ }^{--}$mice exhibited lymphocytosis accompanied by a reduced population of peripheral lymphoid organs, a phenotype indicative of a failure of lymphocyte migration out of the blood as a consequence of reduced integrin activation. Cell migration requires anterior-posterior polarization of processes such as integrin

15 activation and of actin dynamics to support directional migration(Ridley et al., 2003). The MIT complex is localized to and mediates the protrusions that form at the leading edge of migrating cells(Lagarrigue et al., 2015; Lee et al., 2013), a site at which a4 integrins can anchor Type I Protein Kinase A (PKA)(Lim et al., 2007; Lim et al., 2008) to enable PKA activation. PKA phosphorylation of RhoA forms

20 protrusion-retraction pacemaker at the leading edge of migrating cells(Tkachenko et al., 2011). PTSN, by opposing PKA-mediated Rap1 phosphorylation, can preserve stability of the MIT complex at sites of increased PKA activity such as the leading edge(Lim et al., 2008). Conversely, over-expression of phospho-resistant 
Rap1 can arrest migration(Takahashi et al., 2013), suggesting that the dynamic interplay between PKA and PTSN in Rap1 phosphorylation can contribute to the protrusion-retraction cycles that govern cell migration.

5 Pre-clinical research identified inhibition of ligand binding to lymphocyte integrins as a potential therapeutic target in autoimmune and inflammatory diseases(Dustin, 2019; von Andrian and Engelhardt, 2003). This idea was validated by the success of vedolizumab anti- $\alpha_{4} \beta_{7}$ in IBD(Feagan et al., 2013), natalizumab anti- $\alpha_{4} \beta_{1}$ in multiple sclerosis(Rice et al., 2005), and efalizumab anti- $\alpha\left\llcorner\beta_{2}\right.$ in psoriasis(Dedrick

10 et al., 2002). Serious mechanisms-based toxicities such as progressive multifocal leukoencephalopathy have limited the use of natalizumab and efalizumab. Inhibition of integrin signaling can preserve some integrin function and can therefore ameliorate mechanism-based toxicities of complete blockade of integrin function(Feral et al., 2006; Petrich et al., 2007). Talin and Rap1 are major elements

15 in signaling pathways that activate leukocyte integrins; however, global loss of talin-1 or combined loss of Rap1a and Rap1b, leads to embryonic lethality in mice(Calderwood et al., 2013; Li et al., 2007). RIAM plays a key role in Rap1dependent talin-mediated activation of $\alpha_{\llcorner} \beta_{2}$ and $\alpha_{4} \beta_{7}$ integrins(Su et al., 2015; Sun et al., 2021) in most leukocytes and lack of RIAM leads to no obvious

20 developmental defects or abnormalities in platelet functions(Klapproth et al., 2015; Stritt et al., 2015; Su et al., 2015). Here we show that PTSN supports Rap1induced assembly of the RIAM-talin-integrin complex required for integrin activation. In the absence of PTSN a defect in lymphocyte trafficking is associated 
with the inability of T cells to provoke experimental colitis. Importantly, like RIAM, PTSN is expressed at low levels in platelets (Fig. 3A) and we observed no gross bleeding tendency or anemia in Apbb1 $\mathrm{ip}^{-/}$mice. Thus, PTSN inhibition may provide a means to blunt immune-mediated inflammation with less mechanism5 based toxicity than direct blockade of ligand binding to leukocyte integrins. 


\section{Acknowledgements}

We thank the UCI and the UCSD Transgenic Mouse Facilities for design help and production of CRISPR modified mice; Jennifer Santini for microscopy technical

5 assistance; and the UCSD School of Medicine Microscopy Core (NINDS P30NS047101). The UCI TMF is a shared resource funded in part by the Chao Family Comprehensive Cancer Center Support Grant (P30CA062203) from the National Cancer Institute. This work was supported by grants HL 139947 and HL 151433 to MHG and by the American Heart Association Career Development

10 Award 18CDA34110228 (F.L.) and Scientist Development Grant 14SDG18440023 (HSL).

Conflict-of-interest disclosure: The authors declare no competing financial interests.

15

\section{Author Contributions}

M.H.G conceived the study, designed experiments, analyzed data, and wrote the manuscript. H.-S.L., H.S. and F.L. designed and executed experiments, analyzed data, and wrote the manuscript. J.W.F and N.E.S. performed mass spectroscopic analysis. A.R.G designed and produced antigen, and tested the antibody

produced. M.H.G, H.-S.L., H.S., F.L., and A.R.G edited the manuscript. 


\section{FIGURE LEGENDS}

Figure 1. PTSN associates with the MIT complex. (A) Schematic of a split

5 tandem affinity purification method to isolate the proteins associated with the MIT complex. 1: U2-OS cells stably expressing integrin allb-streptavidin-binding peptide (SBP) and $\beta_{3}(\mathrm{D} 119 \mathrm{~A})$ to form ligand binding-defective $\alpha_{\Perp \mathrm{l}}(\mathrm{SBP}) \beta_{3}(\mathrm{D} 119 \mathrm{~A})$ were transfected with a plasmid encoding (B) Flag-tagged RIAM, (C) Flag-tagged LPD or (D) No insert. 2: Cell lysis. 3: Anti-Flag affinity chromatography of cell

10 lysates. 4: Native proteins were eluted with 200 $\mu \mathrm{M}$ Flag peptide. 5: The eluate was then passed through a streptavidin column. Bound MIT complexes were washed, eluted with $5 \mathrm{mM}$ biotin and separated by SDS-PAGE. (B-D) Both RIAM- and LPDMIT complexes contain PTSN. All fractions including whole cell lysate (0.5\%), antiFlag flow-through (FT, 0.5\%), Flag eluate (10\%), streptavidin flow-through (FT,

15 10\%) and streptavidin eluate (50\%) were analyzed by immunoblotting. Results are representative of 3 independent experiments.

Figure 2. PTSN regulates integrin activation. (A-B) Silencing of PTSN reduces integrin activation. 293A cells that express constitutively active $\alpha_{\| \mathrm{lb}}(\mathrm{R} 995 \mathrm{~A}) \beta_{3}$ were

20 transduced with a lentivirus encoding a shRNA against PTSN. A scrambled shRNA was used as a negative control. Cells were then transfected with a plasmid encoding either EGFP-tagged shRNA resistant PTSN or EGFP alone. (A) Integrin activation was measured by flow cytometry using the monoclonal antibody PAC1 
that specifically recognizes the activated form of $\alpha_{\text {Ilb }} \beta_{3}$. The activation index was calculated as $(F-F o) /(F m-F o)$, in which $F$ is the geometric mean fluorescence intensity (MFI) of PAC1 binding; Fo is the MFI in presence of the competitive inhibitor integrilin; and Fm is the MFI upon addition of the integrin-activating anti-

5 LIBS6 antibody. Bar graphs represent mean \pm SEM $(n=3$ independent experiments). One-way ANOVA with Tukey post-test; ** $p<0.01$. (B) The expression of PTSN was confirmed by immunoblotting. (C) Domain organization of $\alpha$ - (short) and $\beta$-PTSN (long) isoforms. (D) PTSN $\alpha$ interacts with RIAM. HEK293 cells were transfected with plasmids encoding Flag-tagged $\alpha$ - or $\beta$-PTSN in

10 combination with vectors encoding EGFP-RIAM or EGFP alone prior to anti-Flag affinity chromatography. (E) a-PTSN restores integrin activation in PTSN knockdown cells. The expression of PTSN was silenced in $\alpha_{1 \prime l}(R 995 A) \beta_{3}$ expressing 293A cells and the activation index was determined as in (A). Bar graphs represent mean \pm SEM ( $n=3$ independent experiments). One-way ANOVA

15 with Tukey post-test; ** $p<0.01,{ }^{\star \star \star} p<0.001$.

Figure 3. PTSN enables integrin activation in human T cell line. (A) Relative expression of PTSN and RIAM across various human tissues. Adapted from the Human Proteome Map portal (www.humanproteomemap.org). (B) Knockout of

20 PTSN in Jurkat T cells reduces integrin activation. PPP1R18 gene encoding PTSN was knocked-out in Jurkat T cells using CRISPR/Cas9 and soluble VCAM-1 binding was assessed by flow cytometry. Cellular stimulation was achieved using 25nM PMA. The activation index was calculated as $(F-F o) /(F m-F o)$, in which $F$ 
is the mean fluorescence intensity (MFI) of VCAM-1 binding, Fo in presence of EDTA, and $F m$ upon addition of $\mathrm{MnCl}_{2}$. Bar graphs represent mean $\pm \operatorname{SEM}(\mathrm{n}=3$ independent experiments). Two-way ANOVA with Tukey post-test; ns not

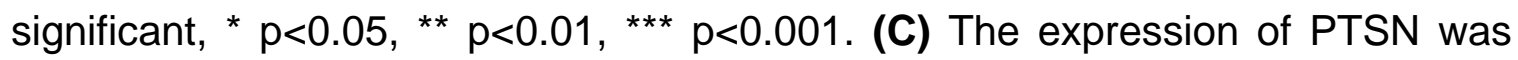

5 confirmed by immunoblotting. Results are representative of 3 independent experiments.

Figure 4. PTSN enables the assembly of the RIAM-MIT complex. (A-B) U2-OS cells that stably express integrin allb-SBP(streptavidin-binding peptide) and

$10 \beta_{3}(\mathrm{D} 119 \mathrm{~A})$ to form ligand binding-defective $\alpha_{\mathrm{Ilb}}(\mathrm{SBP}) \beta_{3}(\mathrm{D} 119 \mathrm{~A})$ were transduced with a lentivirus encoding a shRNA against PTSN prior to transfection with mCherry-tagged $\beta$-PTSN in combination with Flag-RIAM. Flag-tagged RIAM was captured by (A) anti-Flag immunoprecipitation and (B) associated proteins were analyzed by immunoblotting. (C-E) Integrated density values for immunoreactive

15 bands corresponding to integrin $\beta_{3}(\mathbf{C})$, RIAM (D) or talin (E). Bar graphs represent mean \pm SEM ( $n=3$ independent experiments) normalized to control condition (shscrambled). Two-tailed $t$-test; ns not significant, * $p<0.05$.

Figure 5. PTSN mediates Rap1 dephosphorylation. (A) Silencing of PTSN

20 expression promotes Rap1 phosphorylation. $\alpha_{\| \prime}(\mathrm{SBP}) \beta_{3}(\mathrm{D} 119 \mathrm{~A})$ expressing U2OS cells were transduced with a lentivirus encoding a shRNA against PTSN or shCTRL (scrambled) and then transfected with a plasmid encoding Myc-tagged Rap1 in combination with a vector encoding mCherry-tagged PTSNor empty vector. 
Rap1 was immunoprecipitated using an anti-Myc antibody and phosphorylation of Rap1 was revealed by an antibody recognizing phosphorylated PKA substrates (pRap1). (B) As a control, the phosphorylation of CREB was assayed in PTSNdepleted cells using an antibody that specifically recognizes the phosphorylated

5 form of CREB. U2-OS cells were treated with $10 \mu \mathrm{M}$ forskolin for $30 \mathrm{~min}$ to induce CREB phosphorylation. (C) Phosphorylation-resistant Rap1 mutant (S180A) rescues RIAM MIT complex assembly. $\alpha_{\Perp b}(\mathrm{SBP}) \beta_{3}(\mathrm{D} 119 \mathrm{~A})$ expressing U2-OS cells were transduced with a lentivirus encoding a shRNA against PTSN and transfected with a bicistronic plasmid encoding Myc-tagged Rap1 in combination

10 with Flag-RIAM. RIAM was immunoprecipitated using an anti-Flag antibody and the associated $\beta_{3}$ integrin was revealed by immunoblotting. (D) The KISF motif in PTSN binds to the catalytic subunit of protein phosphatase 1 (PP1c). (E) Mutation of the KISF residues into four Ala (4A) in PTSN blocks its interaction with PP1c. HEK293 cells were transfected with plasmids encoding EGFP-tagged PP1c in

15 combination with either $\beta$-PTSN WT or (4A) mutant. PTSN was immunoprecipitated using an anti-Flag antibody prior to immunoblotting. (F-G) HEK293 cells that express constitutively active $\alpha_{\| \mathrm{lb}}(\mathrm{R} 995 \mathrm{~A}) \beta_{3}$ were transduced with a lentivirus encoding a shRNA against PTSN and transfected with a plasmid encoding EGFP-tagged shRNA resistant PTSN either WT or 4A mutant. (F) 293A

20 cells that express constitutively active $\alpha_{\| b}(R 995 A) \beta_{3}$ were transduced with a lentivirus encoding a shRNA against PTSN. A scrambled shRNA was used as a negative control. Cells were then transfected with a plasmid encoding DsRedtagged shRNA resistant $\beta$-PTSN either WT or 4A mutant. Integrin activation was 
measured by flow cytometry using the monoclonal antibody PAC1 that specifically recognizes the activated form of $\alpha_{\| \mathrm{lb}} \beta_{3}$. The activation index was calculated as $(F$ $F o) /(F m-F o)$, in which $F$ is the mean fluorescence intensity (MFI) of PAC1 binding; Fo in presence of the competitive inhibitor integrilin; and Fm upon addition of the

5 integrin-activating anti-LIBS6 antibody. Bar graphs represent mean \pm SEM ( $n=3$ independent experiments). One-way ANOVA with Tukey post-test; ns not significant, ${ }^{\star \star} p<0.01,{ }^{\star \star \star} p<0.001$. (G) The expression of PTSN was confirmed by immunoblotting.

10 Figure 6. Ppp1r18-/- mice are viable with impaired T cell integrin activation. (A) Generation of Ppp1r18 ${ }^{-/-}$mice. Two sgRNAs targeting the exon1 downstream Methionine residue 429 , which drives the expression of a-PTSN, were used in combination with a ssDNA oligo to introduce seven stop codons. (B) Ppp1r18 ${ }^{-/-}$ mice manifest loss of both $\alpha$ - and $\beta$-PTSN isoforms. PTSN expression in

15 splenocytes was assayed by immunoblotting using an antibody that reacts with the C-terminus of PTSN and recognizes both $\alpha$ - and $\beta$-PTSN isoforms. (C) Surface expression of $\alpha_{L}(C D 11 a), \beta_{2}$ (CD18), $\alpha_{4}(C D 49 d), \beta_{1}(C D 29)$ and $\beta_{7}$ integrins, and (D) intracellular staining of RIAM in splenocytes was measured by flow cytometry. Bar graphs represent mean \pm SEM ( $\mathrm{n}=5$ mice). Data are normalized to $P p p 1 r 18^{+/+}$

20 samples. Two-tailed $t$-test; no significant differences were observed. (E-F) Ppp1r18 ${ }^{--}$mice exhibit a leukocytosis. (E) Peripheral blood cell counts of WT or Ppp1r18 ${ }^{--}$mice. Mean \pm SEM are plotted. Two-tailed $t$-test; ${ }^{\star \star} p<0.01 ;{ }^{\star \star \star} \mathrm{p}<0.001$. (F) The number of T and B cells in mesenteric lymph node (MLN), peripheral lymph 
node (PLN) and spleen (SPL) from WT or Ppp1r18-/- mice. Data are normalized to Ppp1r18 ${ }^{+/+}$samples. Bar graphs represent mean \pm SEM ( $\mathrm{n}=4$ mice). Two-tailed t-test; * $p<0.05,{ }^{* \star} p<0.01,{ }^{\star * \star} p<0.001$. (G-J) Loss of PTSN reduces T and B cell adhesion. CD4 ${ }^{+}$T cells (G-I) or B cells $(\mathbf{J})$ were isolated from the spleen of WT or

5 Ppp1r18 ${ }^{-/-}$mice. Cell adhesion to immobilized ICAM-1, VCAM-1 or MAdCAM-1 was assayed in flow condition upon stimulation with SDF-1 $\alpha$. Rest, no stimulation. Bar graphs represent mean \pm SEM ( $n=5$ mice). Two-tailed $t$-test; * $p<0.05$, ** $p<0.01,{ }^{\star * \star} p<0.001$

10 Figure 7. Loss of PTSN expression protects mice from colitis. Conventional T cells $\left(1.10^{6}\right)$ from WT or Ppp1r18\%-/- mice were adoptively transferred into Rag1/mice. (A) Changes in body weight are shown. Values are normalized as a percentage of the original weight. (B) Percent survival. Significant differences were determined using a two-way ANOVA with Bonferroni post-test. (C) Representative

15 hematoxylin and eosin staining of distal colon sections wrapped as swiss rolls from Rag1 $^{-/-}$mice injected with conventional T cells from WT or Ppp1r18 ${ }^{-/-}$mice at Day

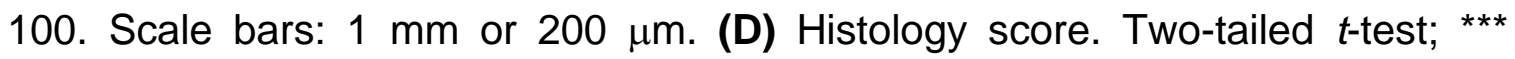
$p<0.001$. (E) mRNA expression of IL-1ß, TNF- $\alpha$, IL-6, IFN- $\gamma$ and IL-17A in distal colon tissues at Day 100. Results are normalized to expression of GAPDH. Mean $20 \pm$ SEM are plotted. Two-tailed t-test; ** $p<0.01,{ }^{\star \star *} p<0.001$ 


\section{SUPPLEMENTARY FIGURE LEGENDS}

Figure S1. PTSN regulates the phosphorylation of Cofilin and VASP. (A-C) U2-OS cells were transduced with a lentivirus encoding a shRNA against PTSN.

5 A scrambled shRNA was used as a negative control. (B) Endogenous VASP was captured by immunoprecipitation. (C) Cells were transfected with a plasmid encoding either Flag-tagged $\alpha$ - or $\beta$-PTSN isoforms. (D-E) Lysates of splenocytes isolated from WT or Ppp1r18 ${ }^{-/}$mice. (A-E) Phosphorylation of Cofilin and VASP were analyzed by immunoblotting using antibodies that specifically recognize the

10 phosphoproteins. Results are representative of 3 independent experiments.

Figure S2. Alternative generation of Ppp1r18-- mice. (A) Generation of Ppp1r18\% mice by deleting the whole coding sequence of exon1. Four sgRNAs targeting the exon1 were used. The edited sequence of the repaired Ppp $1 r 18^{-/}$

15 allele is shown. (B) Ppp1r18\%- mice manifest loss of both $\alpha$ - and $\beta$-PTSN isoforms. PTSN expression in splenocytes was assayed by immunoblotting using an antibody that reacts with the C-terminus of PTSN and recognizes both $\alpha$ - and $\beta$ PTSN isoforms.

20 Figure S3. Deletion of the PTSN $\beta$ isoform in mice leads to intact T cell integrin activation. (A) Generation of $P p p 1 r 18 \beta^{-/}$mice. Two sgRNAs targeting the exon1 in between Methionine residues 1 and 429, which drive the expression of $\beta$ - and $\alpha$-PTSN isoforms, respectively. Edition led to a 10 -base pair deletion 
resulting in an early stop codon. (B) $P p p 1 r 18 \beta^{-/-}$mice manifest loss of the PTSN $\beta$ isoform, but not the a-PTSN isoform. PTSN expression in splenocytes was assayed by immunoblotting using an antibody that reacts with the C-terminus of PTSN and recognizes both $\alpha$ - and $\beta$-PTSN isoforms. (C-D) Surface expression of $\alpha_{L}(C D 11 a), \beta_{2}$ (CD18), $\alpha_{4}$ (CD49d), $\beta_{1}$ (CD29) and $\beta_{7}$ integrins (C) or intracellular staining of RIAM (D) in splenocytes was measured by flow cytometry. Bar graphs represent mean \pm SEM ( $\mathrm{n}=3$ mice). Data are normalized to $P p p 1 r 18 \beta^{+/+}$samples. Two-tailed $t$-test; no significant differences were observed. (E) Ppp1r18$\beta^{-/-}$mice exhibit normal peripheral blood cell counts. Mean \pm SEM are plotted. Two-tailed $t$ -

10 test; no significant differences were observed. (F) The number of T and B cells in mesenteric lymph node (MLN), peripheral lymph node (PLN) and spleen (SPL) from WT or Ppp1r18 $\beta^{-/-}$mice. Data are normalized to $P p p 1 r 18 \beta^{+/+}$samples. Bar graphs represent mean \pm SEM ( $n=4$ mice). Two-tailed $t$-test; no significant differences were observed. (G-H) Deletion of Ppp1r18 $\beta^{-/-}$does not impair T cell

15 adhesion. CD4 ${ }^{+} \mathrm{T}$ cells were isolated from the spleen of WT or Ppp1r18 $\beta^{-/-}$mice. Cell adhesion to immobilized ICAM-1 or VCAM-1 was assayed in flow condition upon stimulation with SDF-1a. Rest, no stimulation. Bar graphs represent mean \pm SEM ( $\mathrm{n}=6$ mice). Two-tailed $t$-test; no significant differences were observed. 


\section{REFERENCES}

Bos, J.L. (2005). Linking Rap to cell adhesion. CurrOpinCell Biol 17, 123.

Boussiotis, V.A., Freeman, G.J., Berezovskaya, A., Barber, D.L., and Nadler, L.M. (1997).

5 Maintenance of human T cell anergy: blocking of IL-2 gene transcription by activated Rap1. Science 278, 124.

Calderwood, D.A., Campbell, I.D., and Critchley, D.R. (2013). Talins and kindlins: partners in integrin-mediated adhesion. Nature reviews Molecular cell biology 14, 503-517.

Dedrick, R.L., Walicke, P., and Garovoy, M. (2002). Anti-adhesion antibodies efalizumab, 10 a humanized anti-CD11a monoclonal antibody. Transpl Immunol 9, 181-186.

Dustin, M.L. (2019). Integrins and Their Role in Immune Cell Adhesion. Cell 177, 499-501.

Erben, U., Loddenkemper, C., Doerfel, K., Spieckermann, S., Haller, D., Heimesaat, M.M., Zeitz, M., Siegmund, B., and Kuhl, A.A. (2014). A guide to histomorphological evaluation of intestinal inflammation in mouse models. Int J Clin Exp Pathol 7, 4557-4576.

15 Feagan, B.G., Rutgeerts, P., Sands, B.E., Hanauer, S., Colombel, J.F., Sandborn, W.J., Van Assche, G., Axler, J., Kim, H.J., Danese, S., et al. (2013). Vedolizumab as induction and maintenance therapy for ulcerative colitis. N Engl J Med 369, 699-710.

Feral, C.C., Rose, D.M., Han, J., Fox, N., Silverman, G.J., Kaushansky, K., and Ginsberg, M.H. (2006). Blocking the alpha 4 integrin-paxillin interaction selectively impairs

20 mononuclear leukocyte recruitment to an inflammatory site. J ClinInvest 116, 715.

Frelinger, A.L., III, Cohen, I., Plow, E.F., Smith, M.A., Roberts, J., Lam, S.C.T., and Ginsberg, M.H. (1990). Selective inhibition of integrin function by antibodies specific for ligand-occupied receptor conformers. Journal of Biological Chemistry 265, 6346.

Frelinger, A.L., III, Du, X., Plow, E.F., and Ginsberg, M.H. (1991). Monoclonal antibodies

25 to ligand-occupied conformers of integrin alpha IIb beta 3 (Glycoprotein IIb-IIIa) alter receptor affinity, specificity, and function. Journal of Biological Chemistry 266, 17106.

Frelinger, A.L., III, Lam, S.C.T., Plow, E.F., Smith, M.A., Loftus, J.C., and Ginsberg, M.H. (1988). Occupancy of an adhesive glycoprotein receptor modulates expression of an antigenic site involved in cell adhesion. Journal of Biological Chemistry 263, 12397.

30 Goldfinger, L.E., Ptak, C., Jeffery, E.D., Shabanowitz, J., Han, J., Haling, J.R., Sherman, N.E., Fox, J.W., Hunt, D.F., and Ginsberg, M.H. (2007). An Experimentally Derived Database of Candidate Ras-Interacting Proteins. J ProteomeRes 6, 1806.

Hogg, N., Patzak, I., and Willenbrock, F. (2011). The insider's guide to leukocyte integrin signalling and function. Nature reviews Immunology 11, 416-426. 
Hughes, P.E., Renshaw, M.W., Pfaff, M., Forsyth, J., Keivens, V.M., Schwartz, M.A., and Ginsberg, M.H. (1997). Suppression of integrin activation: A novel function of a Ras/Rafinitiated MAP kinase pathway. Cell 88, 521.

Hynes, R.O. (2002). Integrins: bidirectional, allosteric signaling machines. Cell 110, 673687.

Kao, S.C., Chen, C.Y., Wang, S.L., Yang, J.J., Hung, W.C., Chen, Y.C., Lai, N.S., Liu, H.T., Huang, H.L., Chen, H.C., et al. (2007). Identification of phostensin, a PP1 F-actin cytoskeleton targeting subunit. Biochemical and biophysical research communications 356, 594-598.

10 Kim, C., Ye, F., and Ginsberg, M.H. (2011). Regulation of integrin activation. Annual review of cell and developmental biology 27, 321-345.

Klapproth, S., Sperandio, M., Pinheiro, E.M., Prunster, M., Soehnlein, O., Gertler, F.B., Fassler, R., and Moser, M. (2015). Loss of the Rap-1 effector RIAM results in leukocyte adhesion deficiency due to impaired beta2 integrin function in mice. Blood 126, 2704152712.

Lagarrigue, F., Gertler, F.B., Ginsberg, M.H., and Cantor, J.M. (2017). Cutting Edge: Loss of T Cell RIAM Precludes Conjugate Formation with APC and Prevents Immune-Mediated Diabetes. Journal of immunology (Baltimore, Md : 1950) 198, 3410-3415.

Lagarrigue, F., Vikas Anekal, P., Lee, H.S., Bachir, A.I., Ablack, J.N., Horwitz, A.F., and 20 Ginsberg, M.H. (2015). A RIAM/lamellipodin-talin-integrin complex forms the tip of sticky fingers that guide cell migration. Nature communications 6, 8492.

Lai, N.S., Wang, T.F., Wang, S.L., Chen, C.Y., Yen, J.Y., Huang, H.L., Li, C., Huang, K.Y., Liu, S.Q., Lin, T.H., et al. (2009). Phostensin caps to the pointed end of actin filaments and modulates actin dynamics. Biochemical and biophysical research communications $25387,676-681$.

Lee, H.S., Anekal, P., Lim, C.J., Liu, C.C., and Ginsberg, M.H. (2013). Two Modes of Integrin Activation Form a Binary Molecular Switch in Adhesion Maturation. Molecular biology of the cell $24,1354-1362$.

Lefort, C.T., Rossaint, J., Moser, M., Petrich, B.G., Zarbock, A., Monkley, S.J., Critchley, 30 D.R., Ginsberg, M.H., Fassler, R., and Ley, K. (2012). Distinct roles for talin-1 and kindlin3 in LFA-1 extension and affinity regulation. Blood 119, 4275-4282.

Ley, K., Laudanna, C., Cybulsky, M.I., and Nourshargh, S. (2007). Getting to the site of inflammation: the leukocyte adhesion cascade updated. Nature reviews Immunology 7 , 678-689.

35 Ley, K., Rivera-Nieves, J., Sandborn, W.J., and Shattil, S. (2016). Integrin-based therapeutics: biological basis, clinical use and new drugs. Nature reviews Drug discovery $15,173-183$.

Li, Y., Yan, J., De, P., Chang, H.C., Yamauchi, A., Christopherson, K.W., 2nd, Paranavitana, N.C., Peng, X., Kim, C., Munugalavadla, V., et al. (2007). Rap1a null mice 
have altered myeloid cell functions suggesting distinct roles for the closely related Rap1a and 1b proteins. Journal of immunology (Baltimore, Md : 1950) 179, 8322-8331.

Lim, C.J., Han, J., Yousefi, N., Ma, Y., Amieux, P.S., McKnight, G.S., Taylor, S.S., and Ginsberg, M.H. (2007). alpha4 Integrins are Type I cAMP-dependent protein kinaseanchoring proteins. Nat Cell Biol 4, 415.

Lim, C.J., Kain, K.H., Tkachenko, E., Goldfinger, L.E., Gutierrez, E., Allen, M.D., Groisman, A., Zhang, J., and Ginsberg, M.H. (2008). Integrin-mediated protein kinase A activation at the leading edge of migrating cells. Molecular biology of the cell 19, 49304941.

10 Lin, Y.S., Huang, H.L., Liu, W.T., Lin, T.H., and Huang, H.B. (2014). Identification of the high molecular weight isoform of phostensin. International journal of molecular sciences 15, 1068-1079.

Lin, Y.S., Huang, K.Y., Wang, T.F., Huang, H.L., Yu, H.C., Yen, J.Y., Hung, S.H., Liu, S.Q., Lai, N.S., and Huang, H.B. (2011). Immunolocalization of phostensin in lymphatic 15 cells and tissues. The journal of histochemistry and cytochemistry : official journal of the Histochemistry Society 59, 741-749.

Loftus, J.C., O'Toole, T.E., Plow, E.F., Glass, A., Frelinger, A.L., III, and Ginsberg, M.H. (1990). A $\beta 3$ integrin mutation abolishes ligand binding and alters divalent cationdependent conformation. Science 249, 915.

20 Luo, B.H., Carman, C.V., and Springer, T.A. (2007). Structural basis of integrin regulation and signaling. Annual review of immunology 25, 619-647.

Medrano-Fernandez, I., Reyes, R., Olazabal, I., Rodriguez, E., Sanchez-Madrid, F., Boussiotis, V.A., Reche, P.A., Cabanas, C., and Lafuente, E.M. (2013). RIAM (Rap1interacting adaptor molecule) regulates complement-dependent phagocytosis. Cellular 25 and molecular life sciences : CMLS 70, 2395-2410.

Mombaerts, P., lacomini, J., Johnson, R.S., Herrup, K., Tonegawa, S., and Papaioannou, V.E. (1992). RAG-1-deficient mice have no mature B and T lymphocytes. Cell 68, 869877.

O'Toole, T.E., Katagiri, Y., Faull, R.J., Peter, K., Tamura, R., Quaranta, V., Loftus, J.C., 30 Shattil, S.J., and Ginsberg, M.H. (1994). Integrin cytoplasmic domains mediate inside-out signal transduction. The Journal of cell biology 124, 1047-1059.

Petrich, B.G., Fogelstrand, P., Partridge, A.W., Yousefi, N., Ablooglu, A.J., Shattil, S.J., and Ginsberg, M.H. (2007). The antithrombotic potential of selective blockade of talindependent integrin alphallbbeta3 (platelet GPIIb-IIla) activation. Journal of Clinical 35 Investigation 117, 2250-2259.

Rice, G.P., Hartung, H.P., and Calabresi, P.A. (2005). Anti-alpha4 integrin therapy for multiple sclerosis: mechanisms and rationale. Neurology 64, 1336-1342. 
Ridley, A.J., Schwartz, M.A., Burridge, K., Firtel, R.A., Ginsberg, M.H., Borisy, G., Parsons, J.T., and Horwitz, A.R. (2003). Cell migration: integrating signals from front to back. Science 302, 1704.

Rose, D.M., Cardarelli, P.M., Cobb, R.R., and Ginsberg, M.H. (2000). Soluble VCAM-1

5 binding to alpha 4 integrins is cell type-specific, activation-dependent, and disrupted during apoptosis. Blood 95, 602.

Shattil, S.J., Hoxie, J.A., Cunningham, M., and Brass, L.F. (1985). Changes in the platelet membrane glycoprotein IIb-IIla Complex during platelet activation. Journal of Biological Chemistry 260, 11107.

10 Stritt, S., Wolf, K., Lorenz, V., Vogtle, T., Gupta, S., Bosl, M.R., and Nieswandt, B. (2015). Rap1-GTP-interacting adaptor molecule (RIAM) is dispensable for platelet integrin activation and function in mice. Blood 125, 219-222.

Su, W., Wynne, J., Pinheiro, E.M., Strazza, M., Mor, A., Montenont, E., Berger, J., Paul, D.S., Bergmeier, W., Gertler, F.B., et al. (2015). Rap1 and its effector RIAM are required

15 for lymphocyte trafficking. Blood 126, 2695-2703.

Sun, H., Kuk, W., Rivera-Nieves, J., Lopez-Ramirez, M.A., Eckmann, L., and Ginsberg, M.H. (2020). beta7 Integrin Inhibition Can Increase Intestinal Inflammation by Impairing Homing of CD25(hi)FoxP3(+) Regulatory T Cells. Cellular and molecular gastroenterology and hepatology $9,369-385$.

20 Sun, H., Lagarrigue, F., Wang, H., Fan, Z., Lopez-Ramirez, M.A., Chang, J.T., and Ginsberg, M.H. (2021). Distinct integrin activation pathways for effector and regulatory T cell trafficking and function. The Journal of experimental medicine 218.

Sun, H., Liu, J., Zheng, Y., Pan, Y., Zhang, K., and Chen, J. (2014). Distinct chemokine signaling regulates integrin ligand specificity to dictate tissue-specific lymphocyte homing.

25 Developmental cell 30, 61-70.

Tadokoro, S., Shattil, S.J., Eto, K., Tai, V., Liddington, R.C., de Pereda, J.M., Ginsberg, M.H., and Calderwood, D.A. (2003). Talin binding to integrin beta tails: a final common step in integrin activation. Science 302, 103-106.

Takagi, J., Petre, B.M., Walz, T., and Springer, T.A. (2002). Global conformational 30 rearrangements in integrin extracellular domains in outside-in and inside-out signaling. Cell 110, 599-511.

Takahashi, M., Dillon, T.J., Liu, C., Kariya, Y., Wang, Z., and Stork, P.J. (2013). Protein kinase A-dependent phosphorylation of Rap1 regulates its membrane localization and cell migration. J Biol Chem 288, 27712-27723.

35 Takahashi, M., Li, Y., Dillon, T.J., and Stork, P.J. (2017). Phosphorylation of Rap1 by cAMP-dependent Protein Kinase (PKA) Creates a Binding Site for KSR to Sustain ERK Activation by cAMP. The Journal of biological chemistry 292, 1449-1461. 
Tkachenko, E., Sabouri-Ghomi, M., Pertz, O., Kim, C., Gutierrez, E., Machacek, M., Groisman, A., Danuser, G., and Ginsberg, M.H. (2011). Protein kinase A governs a RhoARhoGDI protrusion-retraction pacemaker in migrating cells. Nat Cell Biol 13, 660-667.

von Andrian, U.H., and Engelhardt, B. (2003). Alpha4 integrins as therapeutic targets in 5 autoimmune disease. N Engl J Med 348, 68-72.

Wang, T.F., Lai, N.S., Huang, K.Y., Huang, H.L., Lu, M.C., Lin, Y.S., Chen, C.Y., Liu, S.Q., Lin, T.H., and Huang, H.B. (2012). Identification and characterization of the actin-binding motif of phostensin. International journal of molecular sciences 13, 15967-15982.

Wegener, K.L., Partridge, A., Han, J., Pickford, A.R., Liddington, R.C., Ginsberg, M.H.,

10 and Campbell, I.D. (2007). Structural basis of integrin activation by talin. Cell 128, 171.

Xiong, J.P., Stehle, T., Diefenbach, B., Zhang, R., Dunker, R., Scott, D.L., Joachimiak, A., Goodman, S.L., and Arnaout, M.A. (2001). Crystal structure of the extracellular segment of integrin alpha Vbeta3. Science 294, 339-345.

Ye, F., Hu, G., Taylor, D., Ratnikov, B., Bobkov, A.A., McLean, M.A., Sligar, S.G., Taylor, 15 K.A., and Ginsberg, M.H. (2010). Recreation of the terminal events in physiological integrin activation. The Journal of cell biology 188, 157-173.

Zhang, Y., Kim, T.H., and Niswander, L. (2012). Phactr4 regulates directional migration of enteric neural crest through PP1, integrin signaling, and cofilin activity. Genes \& development 26, 69-81. 
A

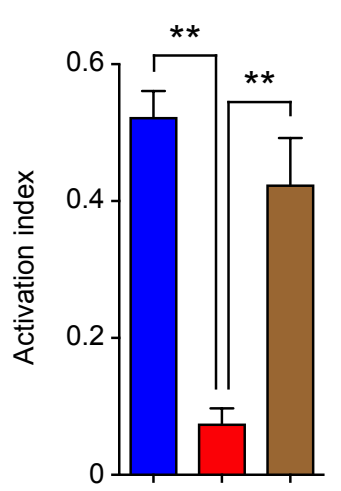

B

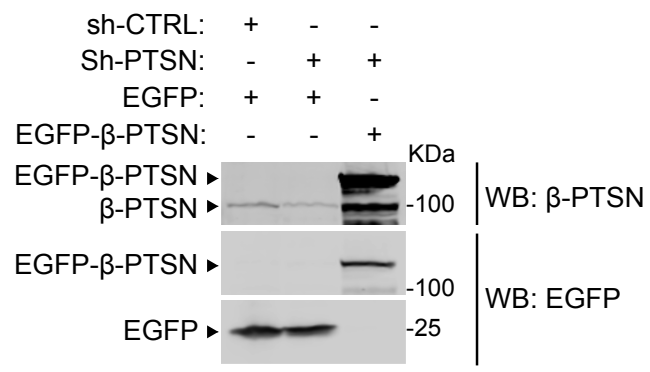

sh-CTRL: + - -

Sh-PTSN: $\quad+\quad+$

EGFP: + + -

C

EGFP-ß-PTSN: - $\quad$ - +

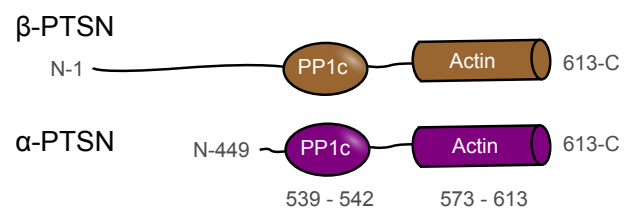

D

E
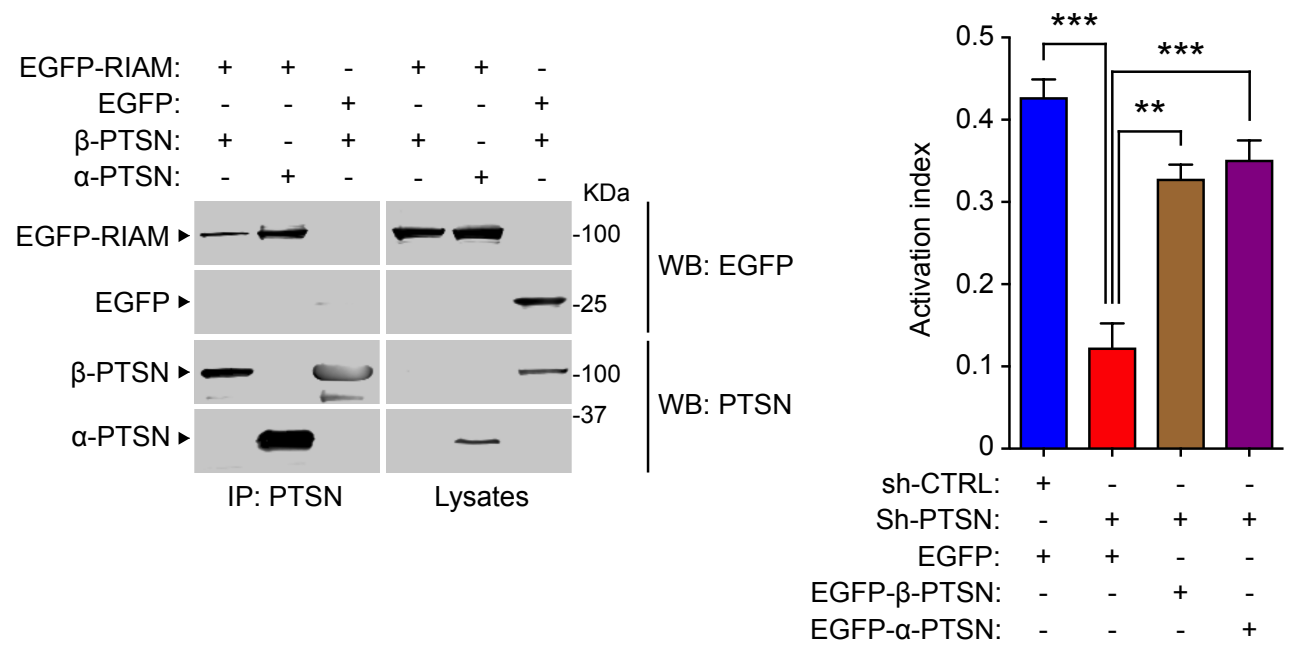


\section{Figure 3}

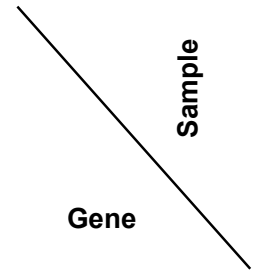

PPP1R18 (PTSN)

APBB1IP (RIAM)

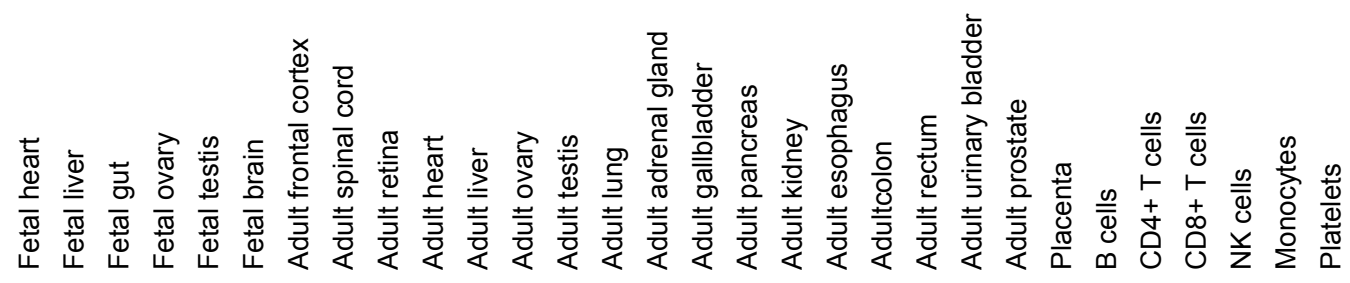

B

$\square$ CTRL + EGFP $\square$ PTSN KO + EGFP- $\beta-P T S N$

$\square$ PTSN KO + EGFP $\square$ PTSN KO + EGFP- $\alpha-P T S N$

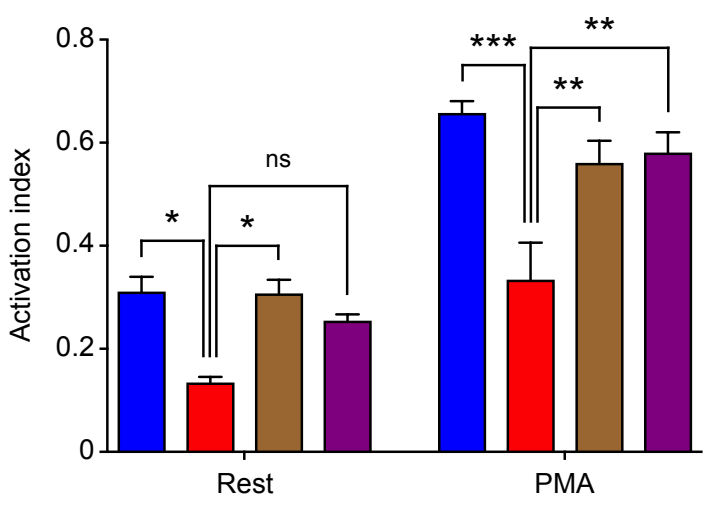

\section{C}

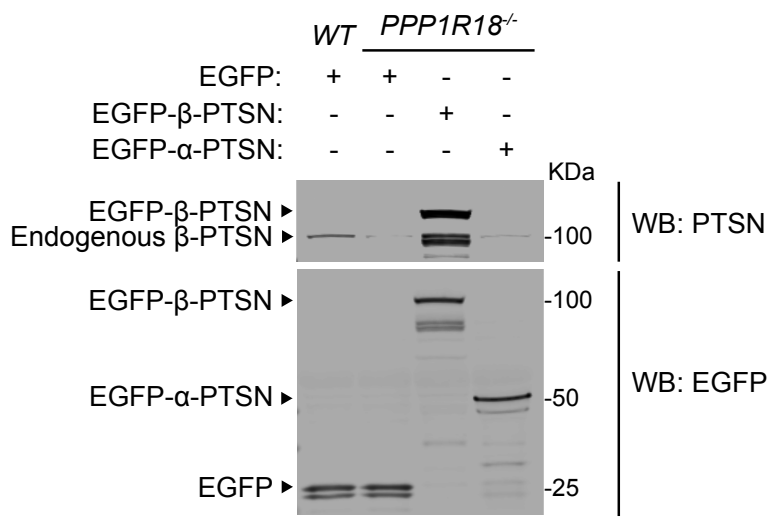


A

Anti-Flag affinity chromatography

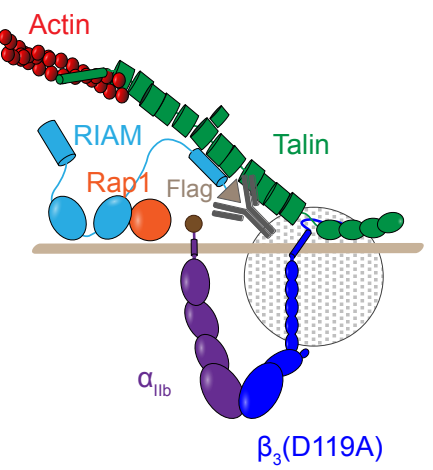

C Integrin $\beta_{3}$

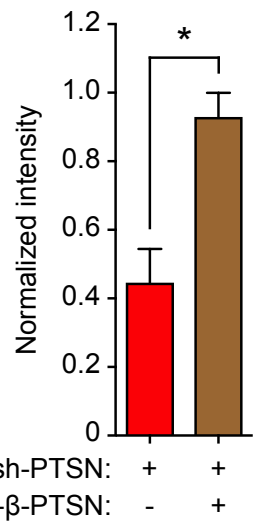

B

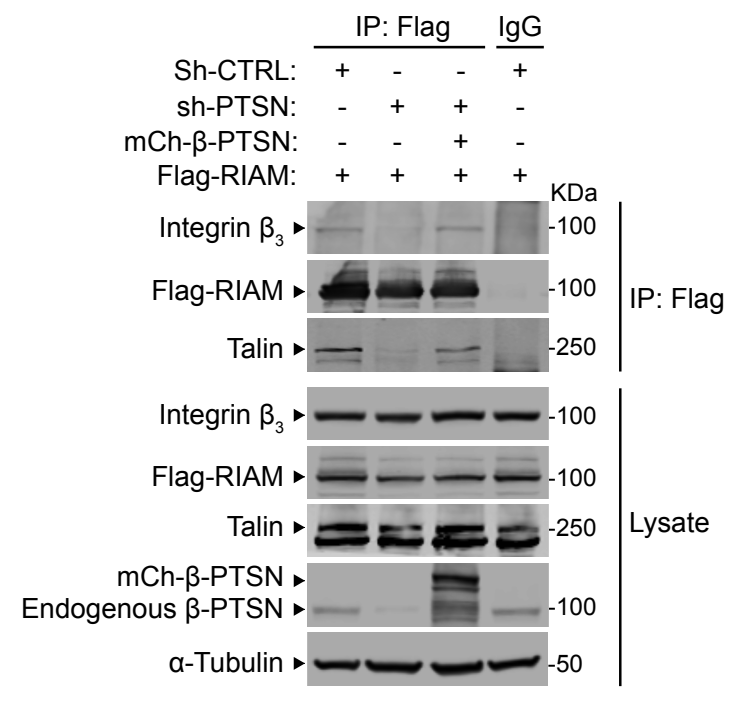

D

RIAM

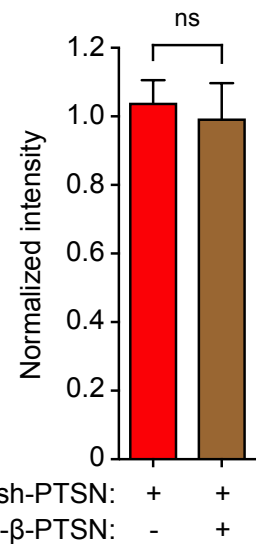

E

Talin

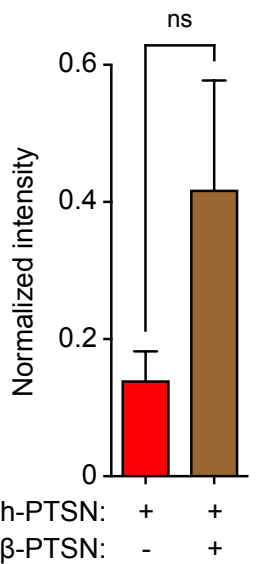


A

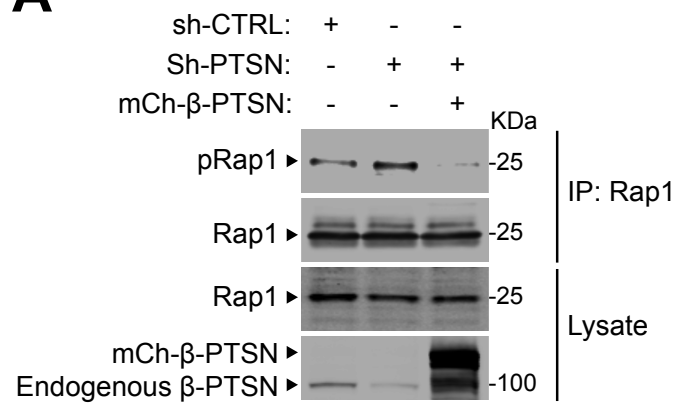

C

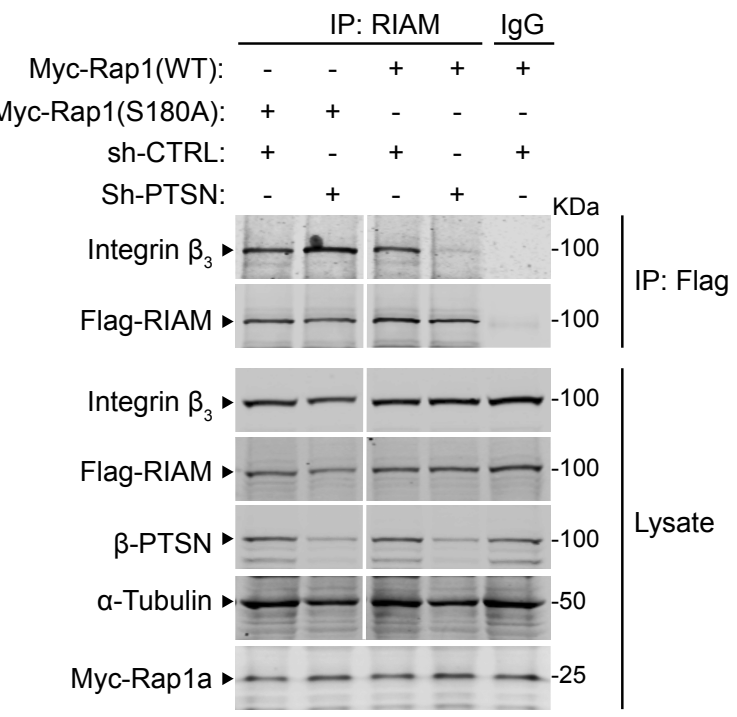

F

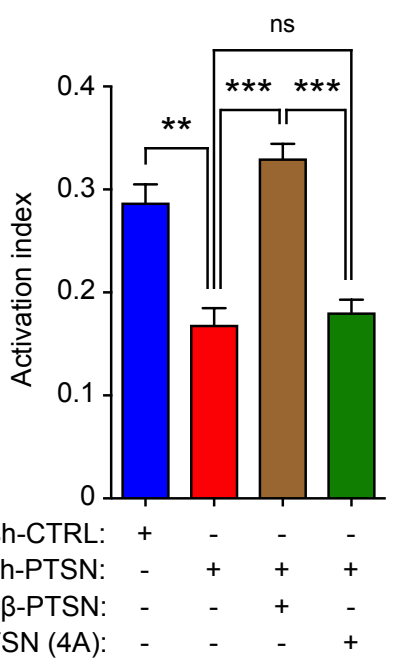

DsRed- $\beta-P T S N ~(4 A)$ :
B

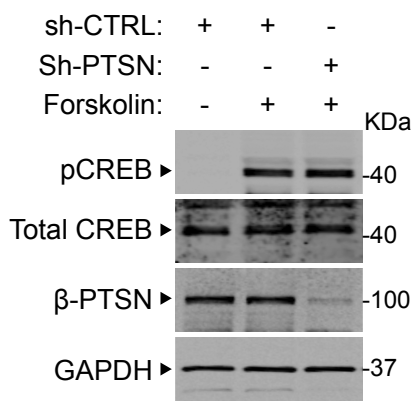

D

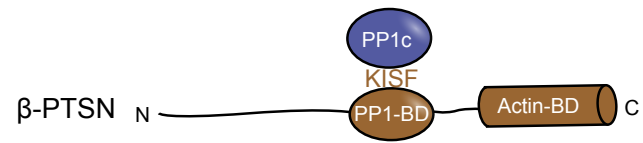

$\beta$-PTSN (4A)

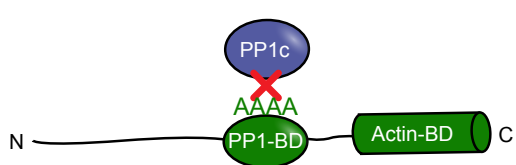

E

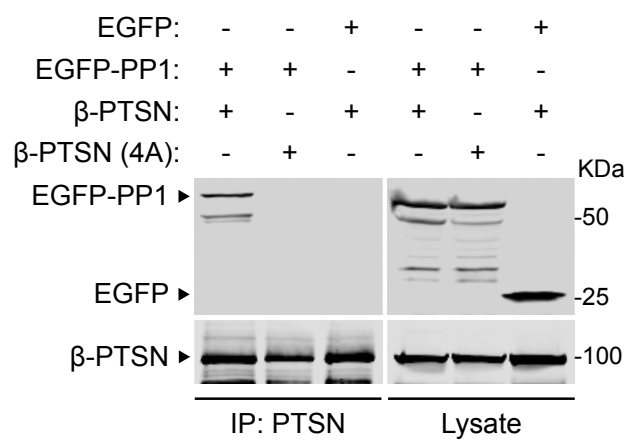

G

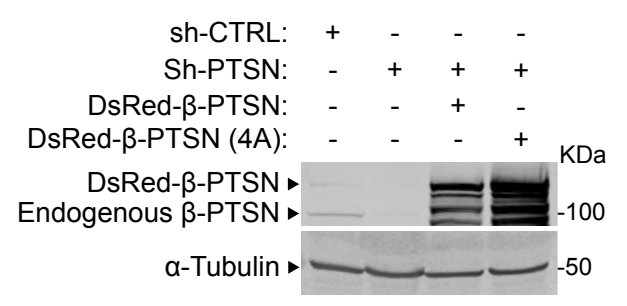




\section{Figure 6}

A

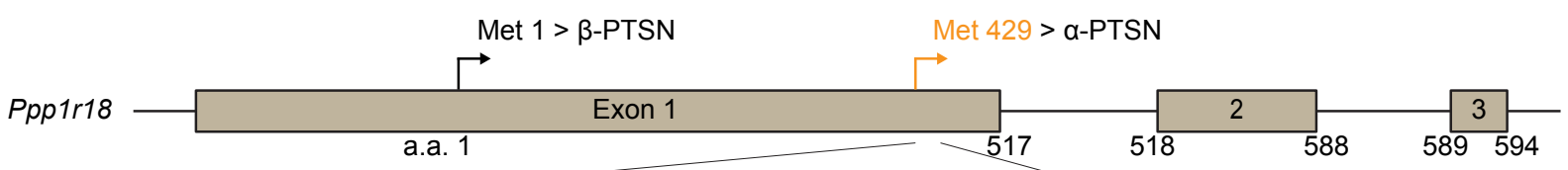

Ppp1r18 $1 /+$

5'.... CTC ATG AGC CGT CTG TTC TAT GGG GTG AAA CCA GGA CCG GGG GTG...

...AAC CCA CGG AGG TGT GCG CCC CCT GCC AGC CCA...3'

«

ssDNA oligo $\quad 5$ '...GTG AAA CCA GGA CCA TGA TAA CTA ATG AGC GCT GAT AAC TGA GAG GTG TGC GCC...3' 46 bp homology

46 bp homology

Stop codons

Ppp1r18 5'...ATG AGC CGT CTG TTC TAT GGG GTG AAA CCA GGA CCA TGA TAA CTA ATG AGC GCT GAT AAC TGA GAG...3'

B

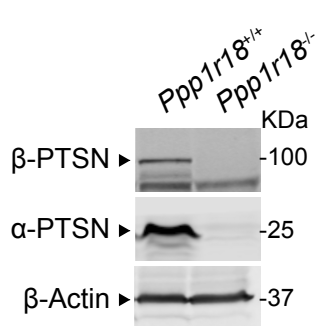

E

WBC
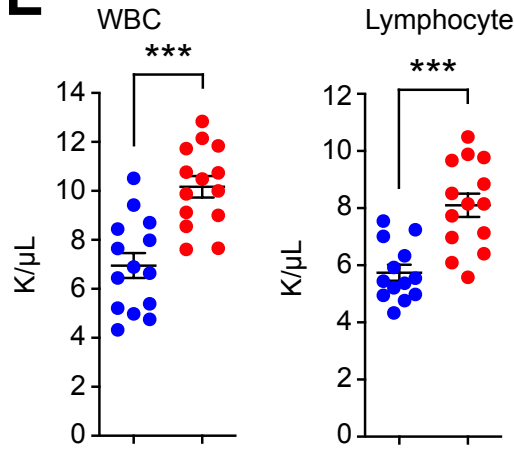

C

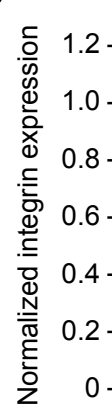

Ppp 1 r1 $8^{+/+}$

$\square$ Ppp1r18

D

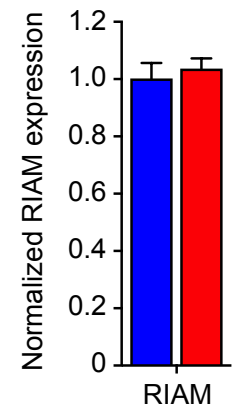

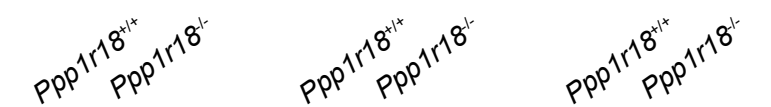

G

ICAM-1

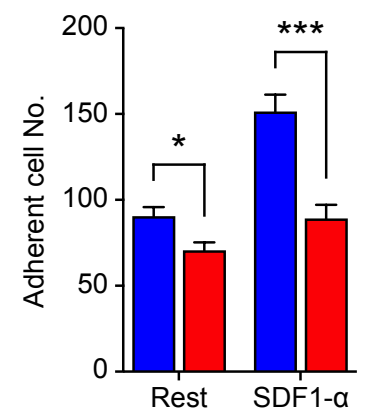

H

VCAM-1

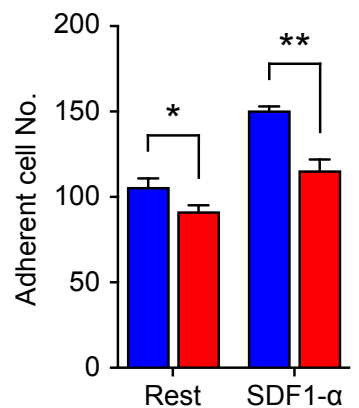

$\mathbf{F}$

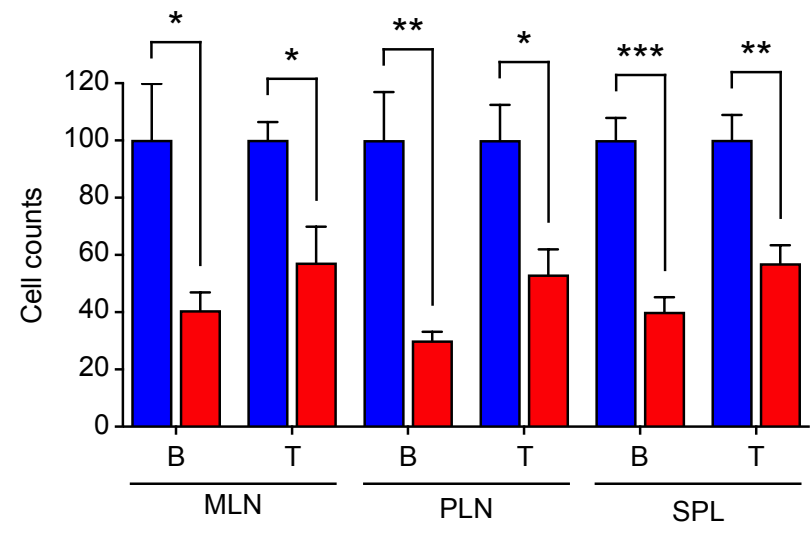

MadCAM-1

J

MadCAM-1

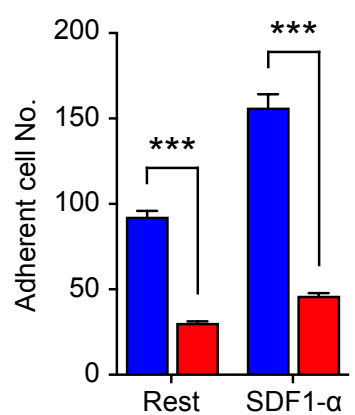

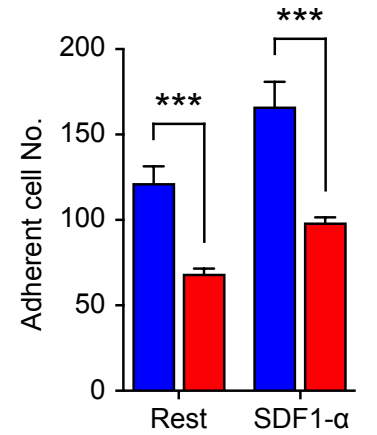


A

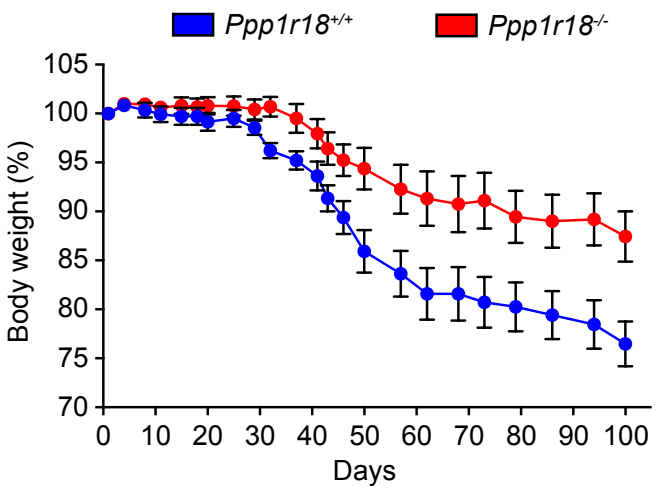

C
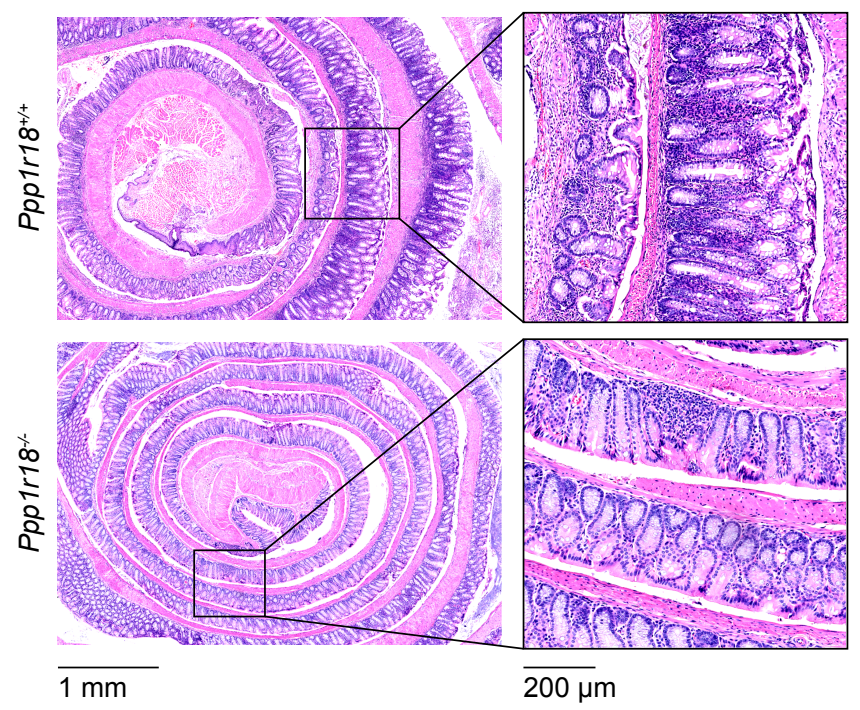

E

IL-1及
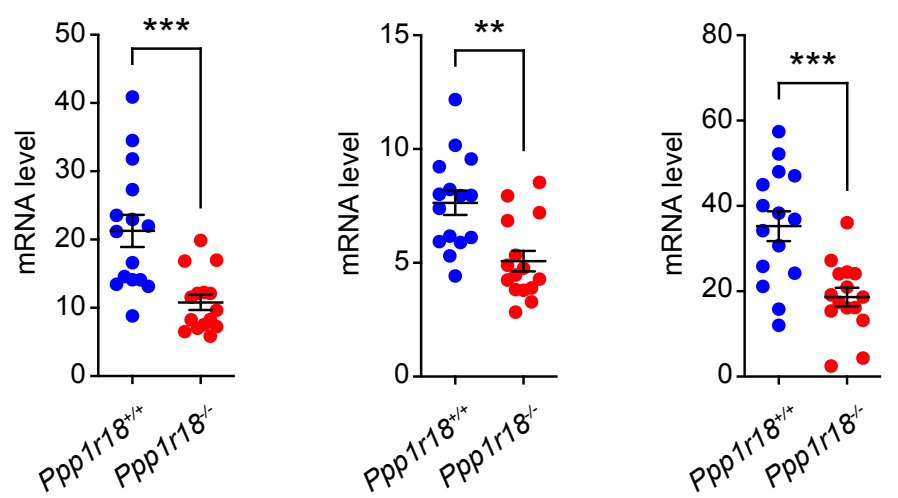

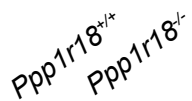

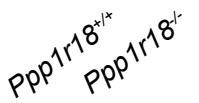

B

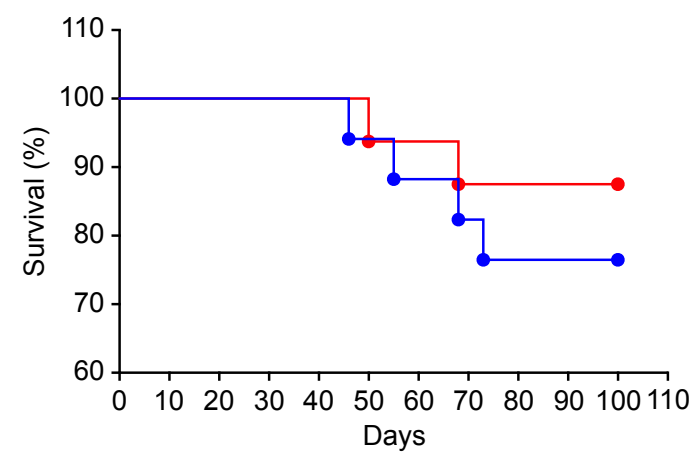

D

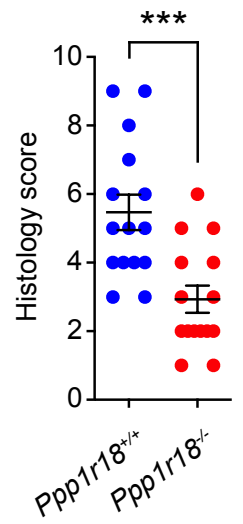

IFN-Y

IL-17A
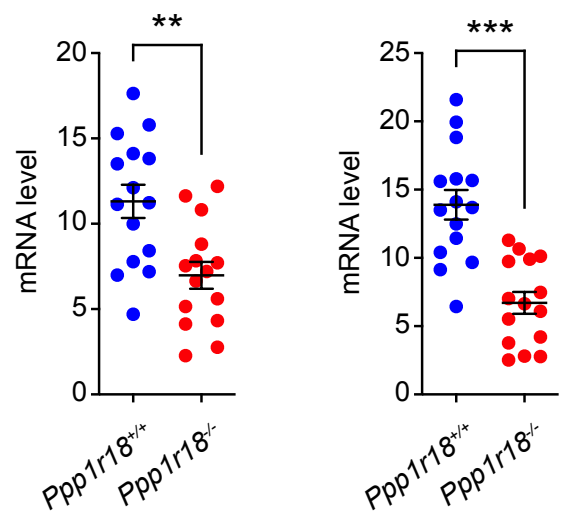
A

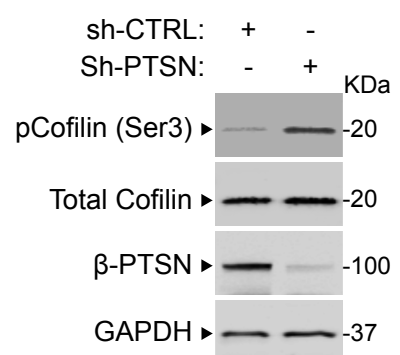

B

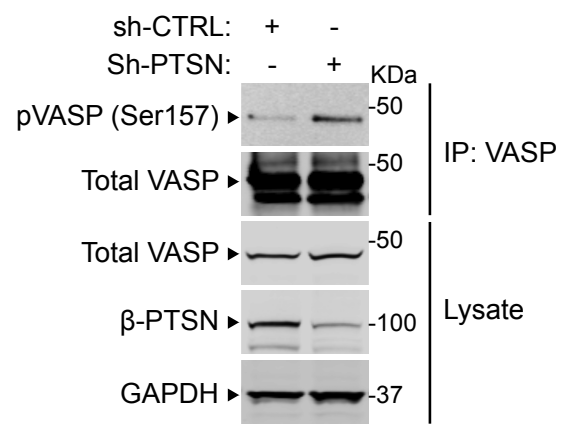

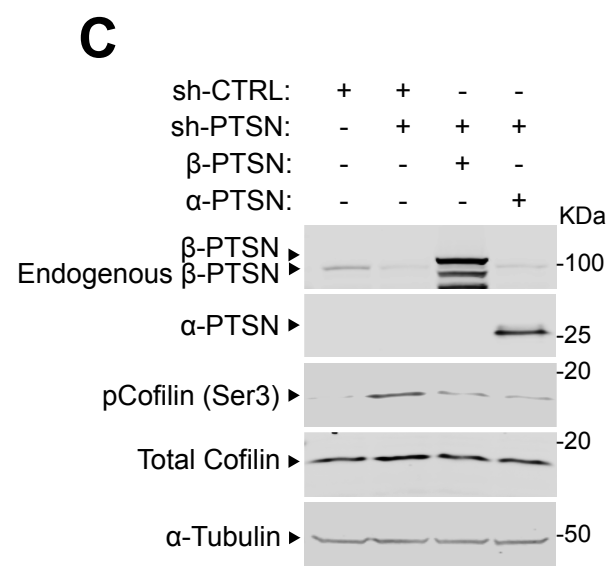

D

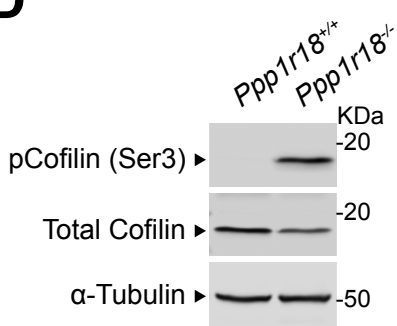

E

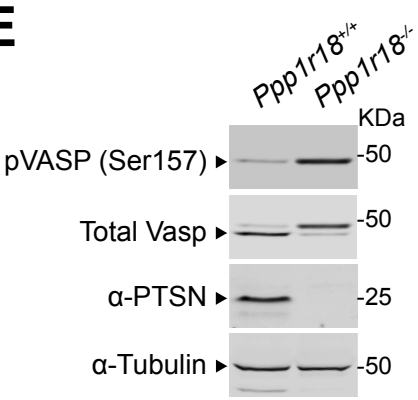




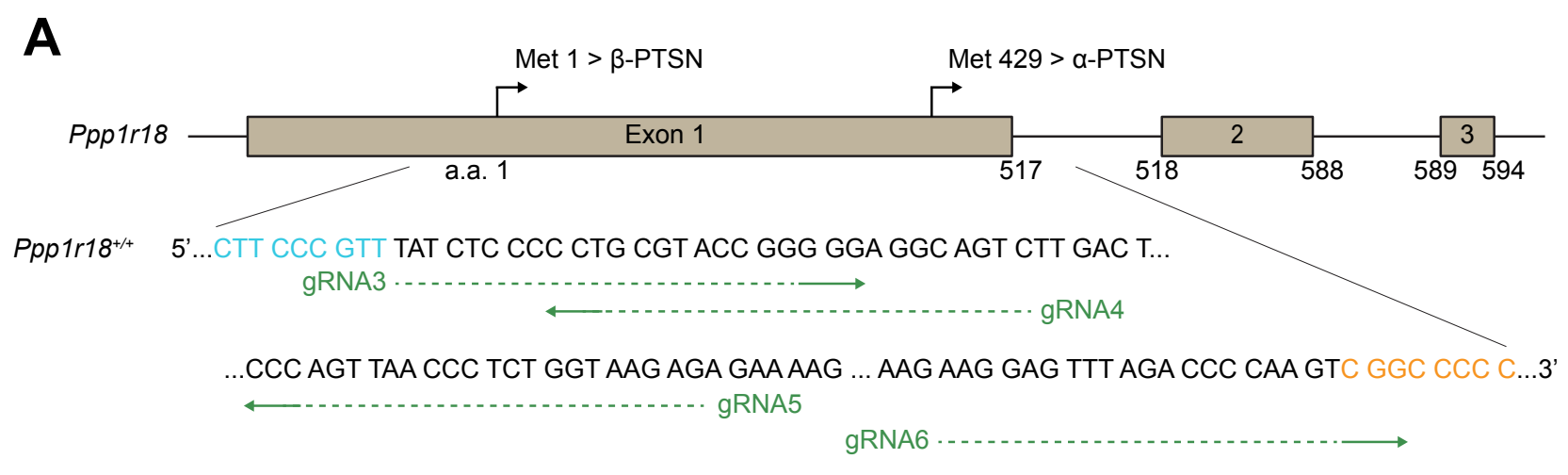

Ppp1r18\% 5'...CCC TTC GCC GTC TGG TTC CCT GTT CTT CCC GTT CGG CCC CCA CTC CTG GCAAGA AGA GGC CAT T...3’

B

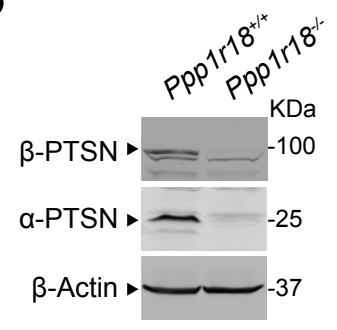




\section{Figure S3}

A

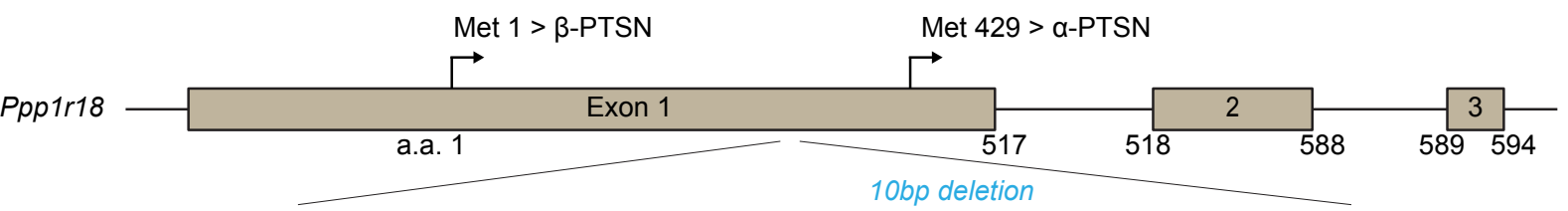

Ppp1r18 ${ }^{+/+} \quad 5^{\prime} . .$. AAC TCT GGG AAG GCT CGA GAA CGG ACG ACC TGG GAC ATA GAT ACA CAAACT...3'

gRNA1

Early Stop

Ppp1r18\% 5'...AAC TCT GGG AAG GCT CGA GAA CGG ACA TAG ATA CAC AAA CT...3'

B

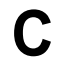

$\square$ Ppp 1 r18 $+/+$

Ppp1r18\%

D
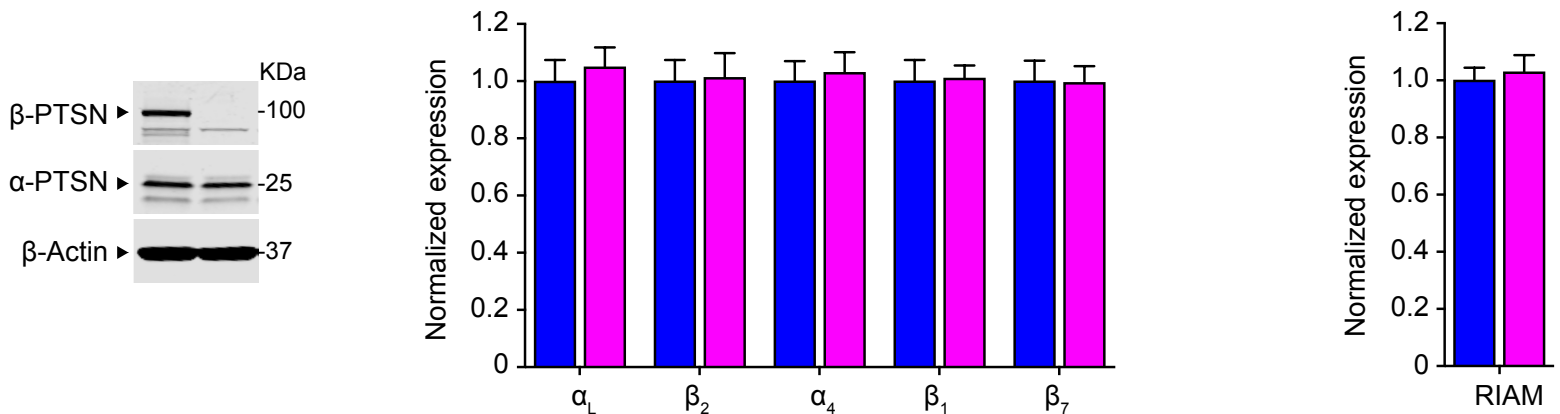

E

E WBC Lymphocytes
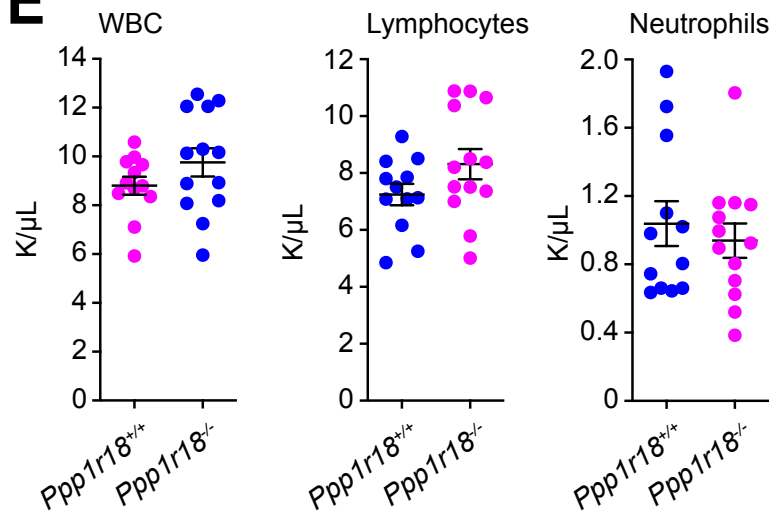

$\mathbf{F}$
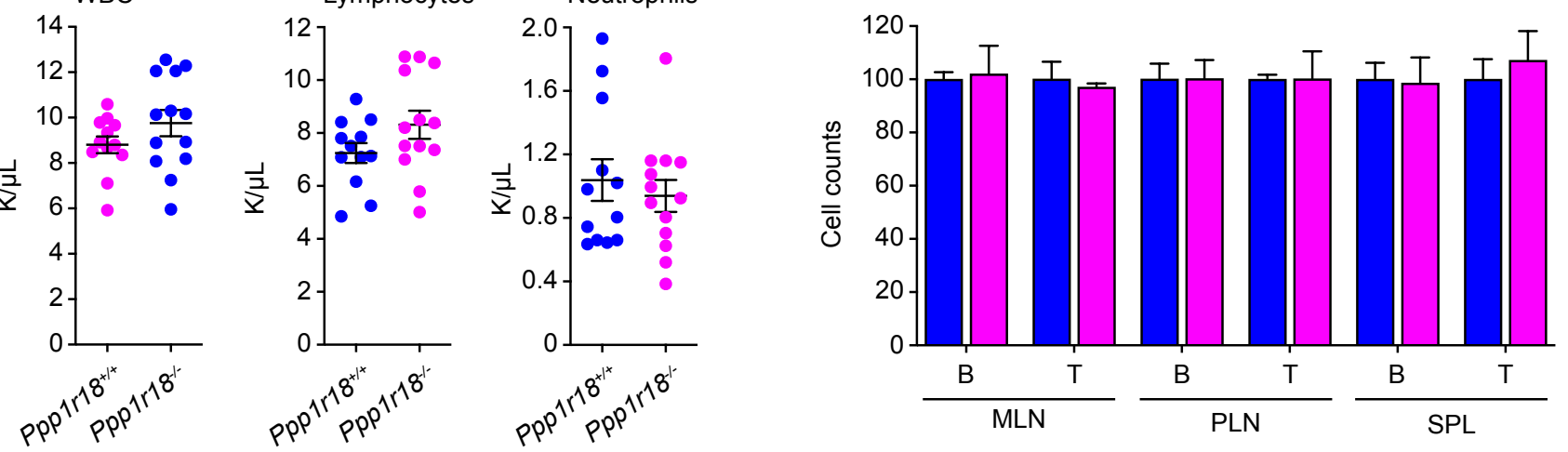

G

ICAM-1

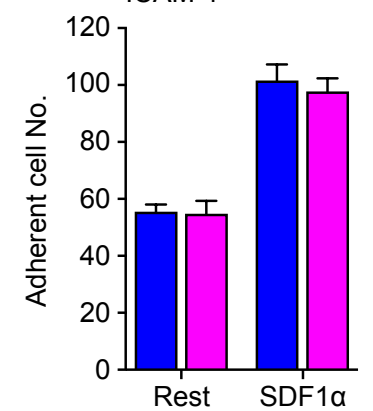

H

VCAM-1

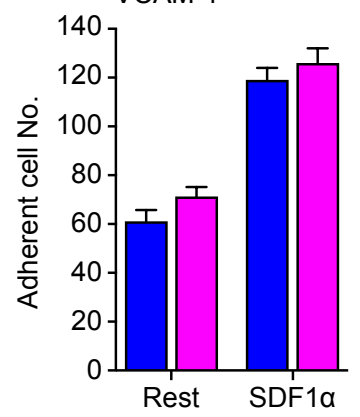

